(NASA-CR-200032) THERMOSPHERIC NITRIC OXIDE FROM THE ATLAS 1 AND

N96-17838

SPACELAB 1 MISSIONS (NASA.

Marshall Space Flight (enter) $25 \mathrm{p}$

Unclas

$63 / 46 \quad 0098263$ 


\title{
Thermospheric nitric oxide from the ATLAS 1 and Spacelab 1 missions
}

\author{
Marsha R. Torr \\ Payload Projects Office, Marshall Space Flight Center, Huntsville, Alabama \\ D. G. Torr, T. Chang, P. Richards, W. Swift, and N. Li \\ Optical Aeronomy Laboratory, University of Alabama in Huntsville
}

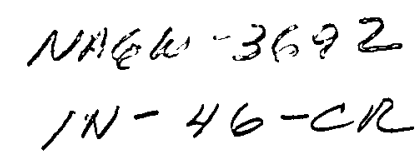

Abstract. Spectral and spatial images obtained with the Imaging Spectrometric Observatory on the ATLAS 1 and Spacelab 1 missions are used to study the ultraviolet emissions of nitric oxide in the thermosphere. By synthetically fitting the measured NO gamma bands, intensities are derived as a function of altitude and latitude. We find that the NO concentrations inferred from the ATLAS 1 measurements are higher than predicted by our thermospheric airglow model and tend to lie to the high side of a number of earlier measurements. By comparison with synthetic spectral fits, the shape of the NO $\gamma$ bands is used to derive temperature as a function of altitude. Using the simultaneous spectral and spatial imaging capability of the instrument, we present the first simultaneously acquired altitude images of NO $\gamma$ band temperature and intensity in the thermosphere. The lower thermospheric temperature images show structure as a function of altitude. The spatial imaging technique appears to be a viable means of obtaining temperatures in the middle and lower thermosphere, provided that good information is also obtained at the higher altitudes, as the contribution of the overlying, hotter NO is nonnegligible. By fitting both self-absorbed and nonabsorbed bands of the NO gamma system, we show that the self absorption effects are observable up to $200 \mathrm{~km}$, although small above $150 \mathrm{~km}$. The spectral resolution of the instrument (1.6 $)$ allows separation of the $\mathrm{N}^{+}\left({ }^{5} S\right)$ doublet, and we show the contribution of this feature to the combination of the NO $\gamma(1,0)$ band and the $\mathrm{N}^{+}\left({ }^{5} S\right)$ doublet as a function of altitude (less than $10 \%$ below $200 \mathrm{~km}$ ). Spectral images including the NO $\delta$ bands support previous findings that the fluorescence efficiency is much higher than that determined from laboratory measurements. The Spacelab 1 data indicate the presence of a significant population of hot NO in the vehicle environment of that early shuttle mission.

\section{Introduction}

An instrument flown on the ATLAS 1 shuttle mission [Torr, 1993] from March 24 to April 2, 1992, obtained spectral images of the nitric oxide gamma bands over latitudes ranging from the equator to approximately $65^{\circ} \mathrm{N}$. The altitudes sampled ranged from 80 to $300 \mathrm{~km}$. The Imaging Spectrometric Observatory (ISO) database provides additional information on this important upper atmospheric constituent. Specifically, the complete NO gamma band system is measured at relatively high spectral resolution, allowing the NO concentrations to be inferred from bands that are not subject to self-absorption and permitting spectral separation from spectrally blended features. The range of latitudes covered exceeds that previously available for the spectral features studied here. In addition to the determination of NO concentrations, the spectra are used to examine the feasibility of using these bands to derive thermospheric temperature profiles. In addition, the twodimensional imaging capability of the instrument allows altitude to be imaged in one dimension, while wavelength is imaged in the other (with all detector pixels being simultaneously exposed), so that in the lower thermosphere/upper

Copyright 1995 by the American Geophysical Union.

Paper number 95JA01040.

0148-0227/95/95JA-01040\$05.00 mesosphere a temperature/concentration altitude image is obtained in each exposure in addition to the spectral image. Both the NO concentrations and temperatures are compared with models. The ATLAS 1 data are compared with similar data obtained during an earlier flight of the instrument on the Spacelab 1 mission in late 1983, which obtained the first simultaneously acquired altitude images of temperature and concentration in the lower thermosphere/upper mesosphere.

The existence of significant NO concentrations in the upper atmosphere was first postulated by Nicolet [1945] in order to explain the measured $D$ region ionization. He pointed out that NO is readily ionized by solar Lyman $\alpha$ radiation. The first measurements of $\mathrm{NO}$ emissions were made almost 20 years later from a rocket $[B a r t h, 1964]$ in which the NO $\gamma(1,0)$ band at $2150 \AA$ was observed with a spectrometer. Further measurements of this feature from rockets and satellites established the photochemistry of NO [Thomas, 1978; Cravens et al., 1979; McCoy, 1983].

NO also plays an important role in the energy budget of the lower thermosphere. Tor et al. [1980b] showed that between 120 and $200 \mathrm{~km}$, the exothermic chemical reaction between $\mathrm{NO}$ and $\mathrm{N}\left({ }^{4} S\right)$ constitutes a major heat source. Kockarts [1980] demonstrated that the $5.3-\mu \mathrm{m}$ radiation from vibrationally excited NO is an effective means of cooling the lower thermosphere. This was quantified in relation to other heating 
Table 1. Relevant Parameters for Far- and Near-UV Imaging Spectrometric Observatory Spectrometers

\begin{tabular}{cccc}
\hline & $\begin{array}{c}\text { Simultaneous } \\
\text { Spectral } \\
\text { Image Range, } \\
\text { Spectrometer }\end{array}$ & $\begin{array}{c}\text { Spectral } \\
\text { Resolution, } \\
\AA\end{array}$ \\
\hline 3 & $2138-4282$ & 236 & 2.3 \\
4 & $1150-2400$ & 177 & 1.6 \\
\hline
\end{tabular}

and cooling rates by Richards et al. [1982] who showed that at altitudes below $150 \mathrm{~km}$, the $5.3-\mu \mathrm{m}$ radiation is the dominant cooling process for the lower thermosphere.

Other studies have characterized the morphological behavior of NO. Work based on the $2150 \AA(1,0)$ NO gamma band measured from the Atmosphere Explorer satellites focused on the diurnal, altitude, and latitudinal morphology [Cravens and Stewart, 1978; Stewart and Cravens, 1978]. These studies found the variability to be largest at high latitudes.

Data from the Solar Mesosphere Explorer satellite [Barth et al., 1988] were used to map the low-latitude variations in NO concentrations at $110 \mathrm{~km}$, indicating a solar maximum to minimum ratio of 7.5. Another study using the Nimbus 7 solar backscattered ultraviolet (SBUV) data [McPeters, 1989], found that the equatorial NO column concentrations above $48 \mathrm{~km}$ increased by a factor of 2 from 1980 to 1986 , with smaller changes at higher latitudes.

At lower altitudes (mesosphere and stratosphere), NO is involved in the catalytic removal of ozone. There is a possible link to the NO produced at higher altitudes at high latitudes as the latter might be transported to lower altitudes during polar winter conditions [Solomon et al., 1982; Solomon and Garcia, 1984].

Much of what we know about NO in the thermosphere is based on measurements of the very bright $(1,0) \gamma$ band at 2150 $\AA$. In the early 1980's there was some concern that these measurements might be compromised by the blended $\mathrm{N}^{+}\left({ }^{5} S\right)$ doublet at 2139/2149 $\AA$ [see Victor and Dalgarno, 1982; Torr and Torr, 1985a]. The $\mathrm{N}^{+}$feature was found to have a substantial effect on the higher-altitude observations and the contribution to the lower thermospheric measurements was relatively small. Cravens [1977] pointed out that the NO concentrations inferred from measurements of the $2150 \AA$ band might be compromised in the lower thermosphere because of the fact that the emission might not be optically thin as had been assumed in earlier studies. The $(1,0)$ transition producing the $2150 \AA$ emission ends in the $v^{\prime}=0$ vibrational level, where the bulk of the NO molecules reside. A study of Spacelab $1 \mathrm{spectral} / \mathrm{spatial}$ images at $100 \mathrm{~km}$ by Erwin [1985] found that when the NO $\gamma$ spectra were synthetically fitted,

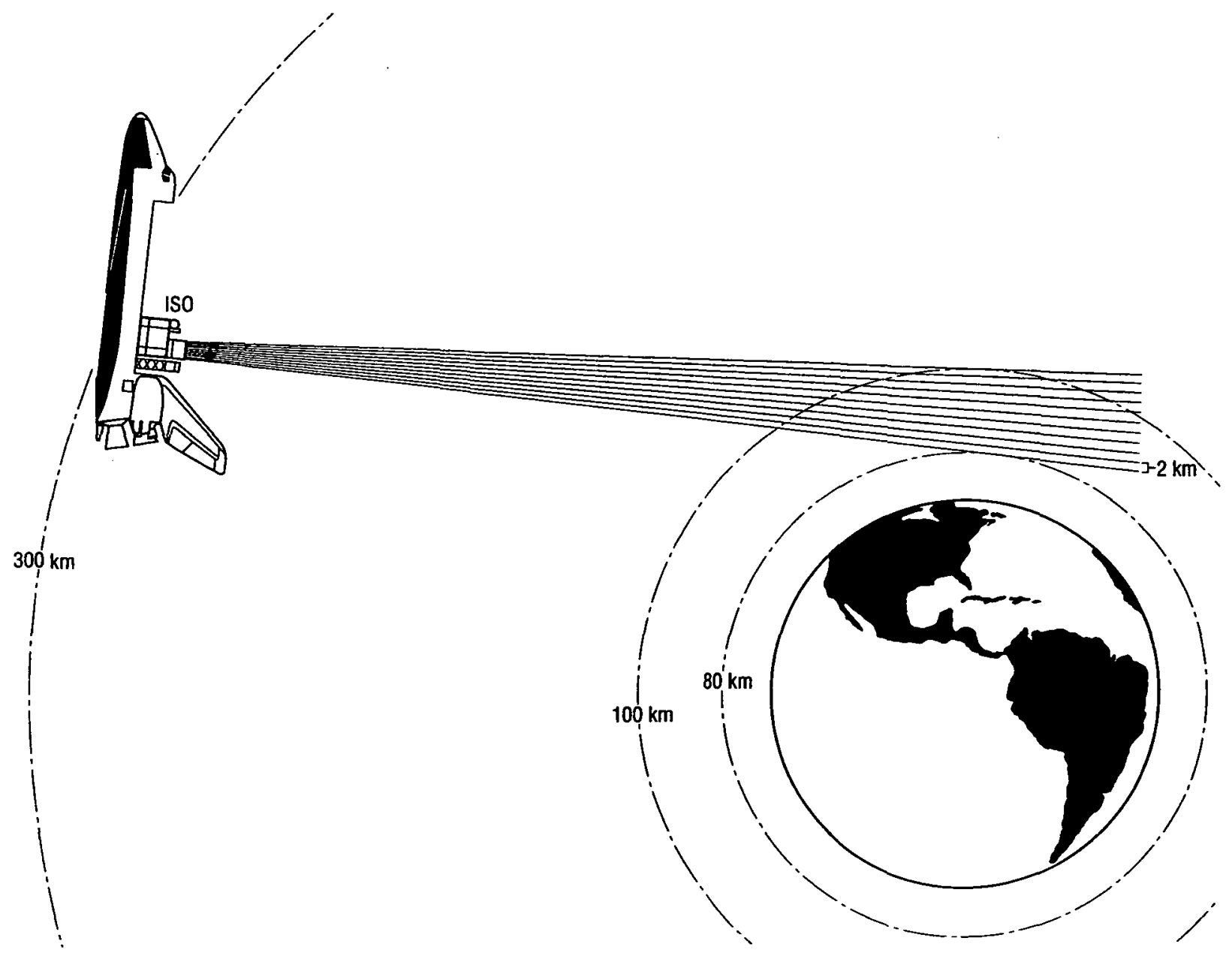

Figure 1. Illustration of the spectral/altitude imaging capability of Imaging Spectrometric Observatory. 


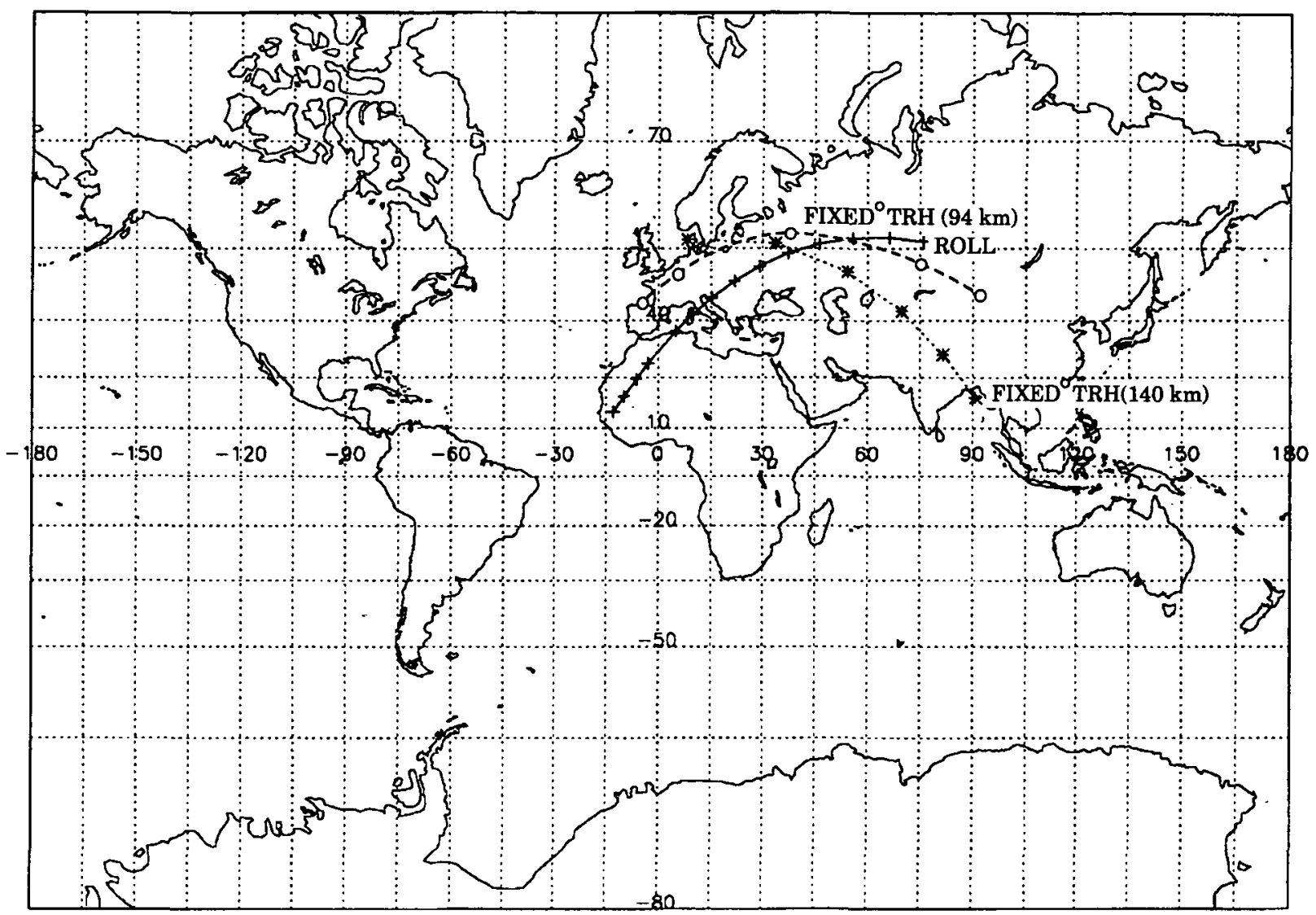

Figure 2. Ground track of tangent ray point during the various sequences used in this study: (dotted-asterisk line) altitude imaging mode with center of field of view at approximately $140 \mathrm{~km}$; (dashed-crossed line) vehicle rolls to sweep field of view down through the atmosphere; (dashed-opened circle line) altitude imaging mode with center of field of view directed at $99 \mathrm{~km}$.

with good fits to the $(1,0)$ and $(2,0)$ bands, that the $(1,1)$ and $(2,2)$ bands were systematically underfitted by the model. Had Erwin fitted the $(1,1)$ and $(2,2)$ bands he would, in fact, have measured the degree of self-absorption of the $(1,0)$ and $(2,0)$ bands. Cleary [1986] derived altitude profiles of NO concentration from the $\gamma(1,0)$ and $(2,0)$ bands. These profiles showed a roll over below $120 \mathrm{~km}$, which the authors presumed to be due to self-absorption. More recently, Eparvier and Barth [1992] reported the results of a high-latitude rocket experiment from which they were able to clearly demonstrate the selfabsorption of the 1-0 band below $130 \mathrm{~km}$ by comparison with the $0-1$ band, as the latter does not end in the 0 vibrational level.

\section{Observational Sequences}

The Imaging Spectrometric Observatory (ISO), flown on the ATLAS 1 mission and the earlier Spacelab 1 mission, comprised five imaging spectrometers. Each spectrometer covered a portion of the wavelength range from the extreme ultraviolet to the near-infrared [Torr et al., 1982, 1983]. The instrument was designed to measure emissions from the thermosphere and mesosphere under sunlit or dark conditions. Two of these spectrometers measured wavelength ranges that contained the various UV bands of NO. The parameters associated with these two spectrometers are summarized in Table 1.

Where the term altitude/spectral image is used, this means a

Table 2. Geophysical Parameters for Sequences Studied

\begin{tabular}{lccc}
\hline \multicolumn{1}{c}{ Parameter } & March 29,1992 & March 25,1992 & March 26,1992 \\
\hline Shuttle attitude & fixed tangent ray height $(\sim 140 \mathrm{~km})$ & fixed tangent ray height $(\sim 99 \mathrm{~km})$ & altitude scan via roll maneuver $(300-105 \mathrm{~km})$ \\
Universal time & $0930-0950$ & $0845-(0902)-0915$ & $07: 18-07: 43$ \\
Local time & $0922-1612$ & $0545-(0852)-1438$ & $05: 22-10: 53$ \\
Solar zenith Angle & $66.6-63.9$ & $94-(58)-62$ & $99.6-55.5$ \\
Latitude & $64.2^{\circ} \mathrm{N}-25.2^{\circ} \mathrm{N}$ & $1^{\circ} \mathrm{N}\left(50^{\circ} \mathrm{N}\right) 46^{\circ} \mathrm{N}$ & $10.5^{\circ} \mathrm{S}-57.0^{\circ} \mathrm{N}$ \\
Longitude & $1.9^{\circ} \mathrm{W}-95.6^{\circ} \mathrm{E}$ & $37^{\circ} \mathrm{W}\left(10^{\circ} \mathrm{E}\right) 92^{\circ} \mathrm{E}$ & $27.9^{\circ} \mathrm{W}-60.8^{\circ} \mathrm{E}$ \\
$\mathrm{F}_{10.7^{-c m} \text { flux }}$ & 193 & 186 & 179 \\
$\mathrm{~F}_{10.7}$ 90-day average & 182 & 189 & 187 \\
$A p$ & 14 & 18 & 13 \\
$K p$ (average) & $3-$ & $3-$ & $2+$ \\
\hline
\end{tabular}


Table 3. Summary of Photochemistry Used in the Airglow Model

\section{Reaction}

Number

(i) $\mathrm{O}^{+}+e \rightarrow \mathrm{O}+h \nu$

$$
\mathrm{O}_{2}+e \rightarrow \mathrm{O}+\mathrm{O}
$$

$\mathrm{O}^{+}+\mathrm{O}_{2} \rightarrow \mathrm{O}_{2}^{+}+\mathrm{O}$

$\mathrm{O}^{+}+\mathrm{N}_{2} \rightarrow \mathrm{NO}^{+}+\mathrm{N}$

(5) $\mathrm{NO}^{+}+e \rightarrow \mathrm{N}+\mathrm{O}$

(6)

$\mathrm{N}_{2}^{+}+\mathrm{O} \rightarrow \mathrm{NO}^{+}+\mathrm{N}$

(8)

(10)

(11)

(12)

(13)
$\mathrm{N}_{2}^{+}+e \rightarrow \mathrm{N}+\mathbf{N}$

$\mathrm{N}_{2}^{+}+\mathrm{O} \rightarrow \mathrm{O}^{+}+\mathrm{N}_{2}$

$\mathrm{N}_{2}^{+}+\mathrm{O}_{2} \rightarrow \mathrm{O}_{2}^{+}+\mathrm{N}_{2}$

$\mathrm{N}^{+}+\mathrm{O}_{2} \rightarrow \mathrm{O}_{2}^{+}+\mathrm{N}^{+}$

$\mathrm{N}^{+}+\mathrm{O}_{2} \rightarrow \mathrm{NO}^{+}+\mathrm{O}$

$\mathrm{N}^{+}+\mathrm{O}_{2} \rightarrow \mathrm{NO}^{+}+\mathrm{O}\left({ }^{1} D\right)$

$\mathrm{O}_{2}^{+}+\mathrm{N} \rightarrow \mathrm{NO}^{+}+\mathrm{O}$

$\mathrm{O}_{2}^{+}+\mathrm{NO} \rightarrow \mathrm{NO}^{+}+\mathrm{O}_{2}$

$\mathrm{O}^{+}\left({ }^{2} D\right)+\mathrm{N}_{2} \rightarrow \mathrm{N}_{2}^{+}+\mathrm{O}$

$\mathrm{O}^{+}\left({ }^{2} D\right)+\mathrm{O} \rightarrow \mathrm{O}^{+}\left({ }^{4} S\right)+\mathrm{O}$

$\mathrm{O}^{+}\left({ }^{2} D\right)+\mathrm{O}_{2} \rightarrow \mathrm{O}_{2}^{+}+\mathrm{O}$

$\mathrm{O}^{+}\left({ }^{2} D\right)+e \rightarrow \mathrm{O}^{+}\left({ }^{4} S\right)+e$

$\mathrm{O}^{+}\left({ }^{2} P\right) \rightarrow \mathrm{O}^{+}\left({ }^{2} D\right)+h \nu$

$\mathrm{O}^{+}\left({ }^{2} P\right) \rightarrow \mathrm{O}^{+}\left({ }^{4} S\right)+h \nu$

$\mathrm{O}^{+}\left({ }^{2} P\right)+e \rightarrow \mathrm{O}^{+}\left({ }^{2} D\right)+e$

$\mathrm{O}^{+}\left({ }^{2} P\right)+e \rightarrow \mathrm{O}^{+}\left({ }^{4} S\right)+e$

$\mathrm{O}^{+}\left({ }^{2} P\right)+\mathrm{N}_{2} \rightarrow$ products

$\mathrm{O}^{+}\left({ }^{2} \mathrm{P}\right)+\mathrm{O} \rightarrow$ products

$\mathrm{He}+h \nu \rightarrow \mathrm{He}^{+}+e$

$\mathrm{He}^{+}+\mathrm{N}_{2} \rightarrow \mathrm{N}^{+}+\mathrm{N}+\mathrm{He}$

$\mathrm{He}++\mathrm{N}_{2} \rightarrow \mathrm{N}_{2}^{+}+\mathrm{He}$

$\mathrm{O}^{+}+\mathrm{H} \rightarrow \mathrm{H}^{+}+\mathrm{O}$

$\mathrm{H}^{+}+\mathrm{O} \rightarrow \mathrm{O}^{+}+\mathrm{H}$

$\mathrm{O}^{+}+\mathrm{N}\left({ }^{2} D\right) \rightarrow \mathrm{N}^{+}+\mathrm{O}$

$\mathrm{NO}^{+}+e \rightarrow \mathrm{N}\left({ }^{2} D\right)+\mathrm{O}$

$\mathrm{N}_{2}^{+}+e \rightarrow \mathrm{N}\left({ }^{2} D\right)+\mathrm{N}$

$\mathrm{N}_{2}^{+}+\mathrm{O} \rightarrow \mathrm{N}\left({ }^{2} D\right)+\mathrm{NO}^{+}$

$\mathrm{N}^{+}+\mathrm{O}_{2} \rightarrow \mathrm{N}\left({ }^{2} D\right)+\mathrm{O}_{2}^{+}$

$\mathrm{N}\left({ }^{2} D\right)+\mathrm{O} \rightarrow \mathrm{N}\left({ }^{4} S\right)+\mathrm{O}$

$\mathrm{N}\left({ }^{2} D\right)+\mathrm{O}_{2} \rightarrow \mathrm{NO}+\mathrm{O}$

$\mathrm{N}\left({ }^{2} D\right)+e \rightarrow \mathrm{N}\left({ }^{4} S\right)+e$

$\mathrm{N}\left({ }^{2} D\right)+\mathrm{O}_{2}^{+} \rightarrow \mathrm{NO}^{+}+\mathrm{O}$

$\mathrm{N}\left({ }^{4} S\right)+\mathrm{O}_{2} \rightarrow \mathrm{NO}+\mathrm{O}$

$\mathrm{N}+\mathrm{NO} \rightarrow \mathrm{N}_{2}+\mathrm{O}$

$\mathrm{O}_{2}+h \nu \rightarrow \mathrm{O}\left({ }^{1} D\right)+\mathrm{O}$

$\mathrm{O}_{2}^{+}+e \rightarrow \mathrm{O}\left({ }^{1} D\right)+\mathrm{O}$

$\mathrm{O}\left({ }^{1} D\right)+\mathrm{N}_{2} \rightarrow \mathrm{O}\left({ }^{3} P\right)+\mathrm{N}_{2}$

$\mathrm{O}\left({ }^{1} D\right)+\mathrm{O}_{2} \rightarrow \mathrm{O}\left({ }^{3} P\right)+\mathrm{O}_{2}$

$\mathrm{O}\left({ }^{1} D\right) \rightarrow \mathrm{O}\left({ }^{3} P\right)+h \nu$

$\mathrm{N}\left({ }^{2} D\right)+\mathrm{O}_{2} \rightarrow \mathrm{O}\left({ }^{1} D\right)+\mathrm{NO}$

$\mathrm{O}_{2}^{+}+e \rightarrow \mathrm{O}\left({ }^{1} S\right)+\mathrm{O}$

$\mathrm{O}_{2}^{+}+\mathrm{N} \rightarrow \mathrm{O}\left({ }^{1} S\right)+\mathrm{NO}^{+}$

$\mathrm{O}\left({ }^{1} S\right)+\mathrm{O}\left({ }^{3} P\right) \rightarrow \mathrm{O}+\mathrm{O}$

$\mathrm{O}\left({ }^{1} S\right)+\mathrm{O} \rightarrow \mathrm{O}+\mathrm{O}$

$\mathrm{O}\left({ }^{1} S\right) \rightarrow \mathrm{O}\left({ }^{1} D\right)+h v$

$\rightarrow \mathrm{O}\left({ }^{3} P\right)+h \nu$

$\mathrm{N}\left({ }^{2} D\right)+\mathrm{NO} \rightarrow \mathrm{N}_{2}+\mathrm{O}$

$\mathrm{O}\left({ }^{1} S\right)+\mathrm{O}_{2} \rightarrow \mathrm{O}\left({ }^{\frac{2}{3}} \mathrm{P}\right)+\mathrm{O}_{2}$

$\mathrm{N}_{2}\left(A^{3} \Sigma_{u}^{+}\right)+\mathrm{O} \rightarrow$ products

$\mathrm{N}_{2}\left(A^{3} \Sigma_{u}^{+}\right)+O \rightarrow O\left({ }^{1} S\right)+\mathrm{N}_{2}$

$\mathrm{N}_{2}^{+}+\mathrm{O} \rightarrow \mathrm{O}^{+}+\mathrm{N}_{2}$

$\mathrm{N}_{2}+h v \rightarrow \mathrm{N}^{+}+\mathrm{N}^{2}+e$

$\mathrm{N}_{2}+h \nu \rightarrow \mathrm{N}_{2}^{+}+e$

Rate Coefficient $\left(\mathrm{cm}^{3} \mathrm{~s}^{-1}\right)$ or Rate $\left(\mathrm{s}^{-1}\right)$

Reference

$\sim 4 \times 10^{-12}(T / 300)^{0.7}$

$1.6 \times 10^{-7}\left(300 / T_{e}\right)^{0.55}$ for $T_{e} \geq 1200 \mathrm{~K}$

$2 \times 10^{-7}\left(300 / T_{e}\right)^{0.7}$ for $T_{e}<1200 \mathrm{~K}$

$2.1 \times 10^{-11}\left\{T_{n}+2 \mathrm{Ti} / 300\right\}^{-0.763}$

$1.533 \times 10^{-12}-5.92 \times 10^{-13}\left(T_{\mathrm{eff}} / 300\right)+$

$8.60 \times 10^{-14}\left(T_{\text {eff }} / 300\right)^{2}$ for $300 \leq T_{\text {eff }} \leq$ $1700 \mathrm{~K}$

$2.73 \times 10^{-12}-1.155 \times 10^{-12}\left(T_{\mathrm{cff}} / 300\right)+$ $1.483 \times 10^{-13}\left(T_{\text {eff }} / 300\right)^{2}$ for $1700<T_{\text {eff }}$ $<6000 \mathrm{~K}$

$4.3 \times 10^{-7}\left(T_{e} / 300\right)^{-1}$

$1.4 \times 10^{-10}(T i / 300)^{-0.44}$ for $T i<1500$

$\mathrm{K}$

$2.7 \times 10^{-7}$

$0.07 k_{6}\left(T_{i} / 300\right)^{0.21}$

$9.1 \times 10^{-11} \exp \left(-0.002 T_{\text {eff }}\right)$

$4 \times 10^{-10}$

$2 \times 10^{-10}$

$\beta=0.7$

$1.2 \times 10^{-10}$

$4.4 \times 10^{-10}$

$8 \times 10^{-10}$

$5 \times 10^{-12}$

$7 \times 10^{-10}$

$6.6 \times 10^{-8}\left(300 / T_{e}\right)^{0.5}$

$0.173 \mathrm{~s}^{-1}$

$0.047 \mathrm{~s}^{-1}$

$1.5 \times 10^{-7}\left(300 / T_{e}\right)^{0.5}$

$4.7 \times 10^{-8}\left(300 / T_{e}\right)^{0.5}$

$3.4 \times 10^{-10}$

$4.0 \times 10^{-10}$

$4.0 \times 10^{-8}-1.2 \times 10^{-7 c}$

$1 \times 10^{-9}$

$6.5 \times 10^{-10}$

$2.2 \times 10^{-11}\left(T_{i}\right)^{0.5}$

$2.5 \times 10^{-11}\left(T_{n}\right)^{0.5}$

$5 \times 10^{-11}$

$\beta k_{5}$, where $\beta=0.76$

$\beta k_{7}$, where $\beta=1.9$

$\beta k_{6}$, where $\beta=1.0$

$\beta k_{10}$, where $\beta=1.0$

$\sim 7 \times 10^{-13}$

$6 \times 10^{-12}$

$5 \times 10^{-10}\left(T_{e} / 300\right)^{0.5}$

$1 \times 10^{-10}$

$4.4 \times 10^{-12} \exp (-3220 / T)$

$3.4 \times 10^{-11}$

$\beta=1 ; \mathrm{J}_{\infty}(\mathrm{O} 2)_{S R}=(1.5-2.8) \times 10^{-6}$

$\beta k_{2}$, where $\beta=1.2$

$2.0 \times 10^{-11} \exp \left(107.8 / T_{n}\right)$

$2.9 \times 10^{-11} \exp \left(67.5 / T_{n}\right)$

0.00934

$\sim 5 \times 10^{-12}$

$\beta k_{2}$, where $\beta=0.08$

$\sim 2 \times 10^{-11}$

$2 \times 10^{-14}$

$8 \times 10^{-12}$

1.07

0.045

$7 \times 10^{-11}$

$4.9 \times 10^{-12} \exp (-1730 / R T)$

$2 \times 10^{-11}$

$\beta k_{54}$, where $\beta=0.37$

$\sim 2 \times 10^{-12 \mathrm{~b}}$

$(1.78-5.14) \times 10^{-18}$

$(3.06-8.82) \times 10^{-7}$
Torr [1985]

Torr and Torr [1981]

Mehr and Biondi [1969]

Chen et al. [1978]

St. Maurice and Tor [1978];

Albritton [1978]; Chen et al. [1978]

Torr and Torr [1979]

McFarland et al. [1974]; Torr [1979]

Abdou et al. [1984]

McFarland et al. [1974]

Lindinger et al. [1974]

Huntress and Anicich [1976]

Huntress and Anicich [1976]

Langford et al. [1985]

Fehsenfeld [1977]

Lindinger et al. [1974]

Rowe et al. [1980]; Johnsen and Biondi [1980]

Abdou et al. [1984]

Johnsen and Biondi [1980]

Henry et al. [1969]

Seaton and Osterbrock [1957]

Seaton and Osterbrock [1957]

Henry et al. [1969]

Henry et al. [1969]

Chang et al. [1993]

Chang et al. [1993]

Torr and Torr [1985]

Adams and Smith [1976]

Adams and Smith [1976

derived from Banks and Kockarts [1973]

derived from Banks and Kockarts [1973]

Torr et al. [1979]

Kley et al. [1977]

Queffelec et al. [1985]

Frederick and Rusch [1977]

assumed

Richards et al. [1981]

Lin and Kauffman [1971]

Frederick and Rusch [1977]

Dalgarno [1970]

Becker et al. [1969]

Lee et al. [1978]

Torr et al. [1980a]

Abreu et al. [1986]

Streit et al. [1976]

Streit et al. [1976]

Fischer and Saha [1983]

Rusch et al. [1978]; Torr et al. [1981]

Bates and Zipf [1981]; Abreu et al. [1986]

Frederick et al. [1976]

Slanger and Black [1981]

Abreu et al. [1986]

Kernahan and Pang [1975]

Lin and Kauffman [1971]

Zipf [1985]

Piper [1982]

Piper [1982]

Abdou et al. [1984]; Torr [1985]

Torr and Torr [1985] 
Table 3. (continued)

\begin{tabular}{|c|c|c|c|}
\hline $\begin{array}{l}\text { Reaction } \\
\text { Number }\end{array}$ & Reaction & Rate Coefficient $\left(\mathrm{cm}^{3} \mathrm{~s}^{-1}\right)$ or Rate $\left(\mathrm{s}^{-1}\right)$ & Reference \\
\hline$(58)$ & $\begin{array}{l}\mathrm{O}+h \nu \rightarrow \mathrm{O}^{+}\left({ }^{4} S\right)+e \\
\mathrm{O}+h \nu \rightarrow \mathrm{O}^{+}\left({ }^{2} D\right)+e \\
\mathrm{O}+h \nu \rightarrow \mathrm{O}^{+}\left({ }^{2} P\right)+e \\
\mathrm{O}+h \nu \rightarrow \mathrm{O}^{+}\left({ }^{4} S\right)+e \\
\mathrm{O}+h \nu \rightarrow \mathrm{O}^{+}\left({ }^{2} P^{c}\right)+e\end{array}$ & $\begin{array}{l}(0.98-2.81) \times 10^{-7} \\
(0.79-2.34) \times 10^{-7} \\
(0.45-1.38) \times 10^{-7} \\
(1.04-3.43) \times 10^{-8} \\
(0.46-1.42) \times 10^{-8}\end{array}$ & Torr and Torr $[1985]^{c}$ \\
\hline $\begin{array}{l}(59) \\
(60)\end{array}$ & $\begin{array}{l}\mathrm{O}\left({ }^{1} D\right)+\mathrm{O} \rightarrow \mathrm{O}\left({ }^{3} P\right)+\mathrm{O} \\
\mathrm{O}+e_{\text {therm }} \rightarrow \mathrm{O}\left({ }^{1} D\right)\end{array}$ & $\begin{array}{l}8 \times 10^{-12} \\
k_{60}=1.1 \times 10^{-10} \sqrt{T_{e}} e^{-2.27 \times 10^{4} / T e} \\
\quad\left[0.406+3.57 \times 10^{-5} T_{e_{4}}-(0.333+\right. \\
\left.\quad 1.83 \times 10^{-5} T e\right) e^{-1.37 \times 10^{4} / T_{e}}-(0.456 \\
\left.\quad+1.74 \times 10^{-5} T e\right) e^{\left.-2.97 \times 10^{4} / r_{e}\right]}\end{array}$ & $\begin{array}{l}\text { Abreu et al. }[1986] \\
\text { Rees et al. }[1967]\end{array}$ \\
\hline
\end{tabular}

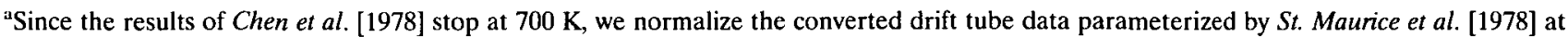
this temperature.

${ }^{b}$ The model computes this rate coefficient as a function of $\mathrm{N}_{2}^{+}$vibrational temperature $(T v)$. The value reduces to that given by (6) when $T v=$ $T n$. Inclusion of this process is an option available.

The ranges given for the ionization frequencies indicate the variation over a solar cycle.
}

Table 4. Summary of Photoionization and Photoelectron Excitation Cross Sections

\begin{tabular}{lll}
\hline \multicolumn{1}{c}{ Type } & \multicolumn{1}{c}{ Species } & \multicolumn{1}{c}{ Reference } \\
\hline Photoionization & $\mathrm{O}$ & Samson and Pareek [1985] \\
& $\mathrm{O}_{2}, \mathrm{~N}_{2}$ & Kirby et al. [1979] \\
Total photoabsorption & $\mathrm{O}_{2}, \mathrm{~N}_{2}$ & Torr et al. [1979] \\
Total electron impact ionization cross sections & $\mathrm{O}_{2}, \mathrm{~N}_{2}$ & see Richards and Torr [1990] \\
Total electron impact excitation cross sections & $\mathrm{O}$ & Zipf and Erdman [1985]; Vaughn \\
& & and Doering [1986] \\
& $\mathrm{N}_{2}$ & Cartwright [1977] \\
& $\mathrm{O}\left({ }^{\prime} D\right), \mathrm{O}\left({ }^{1} S\right)$ & Henry et al. $[1969]$ \\
\hline
\end{tabular}

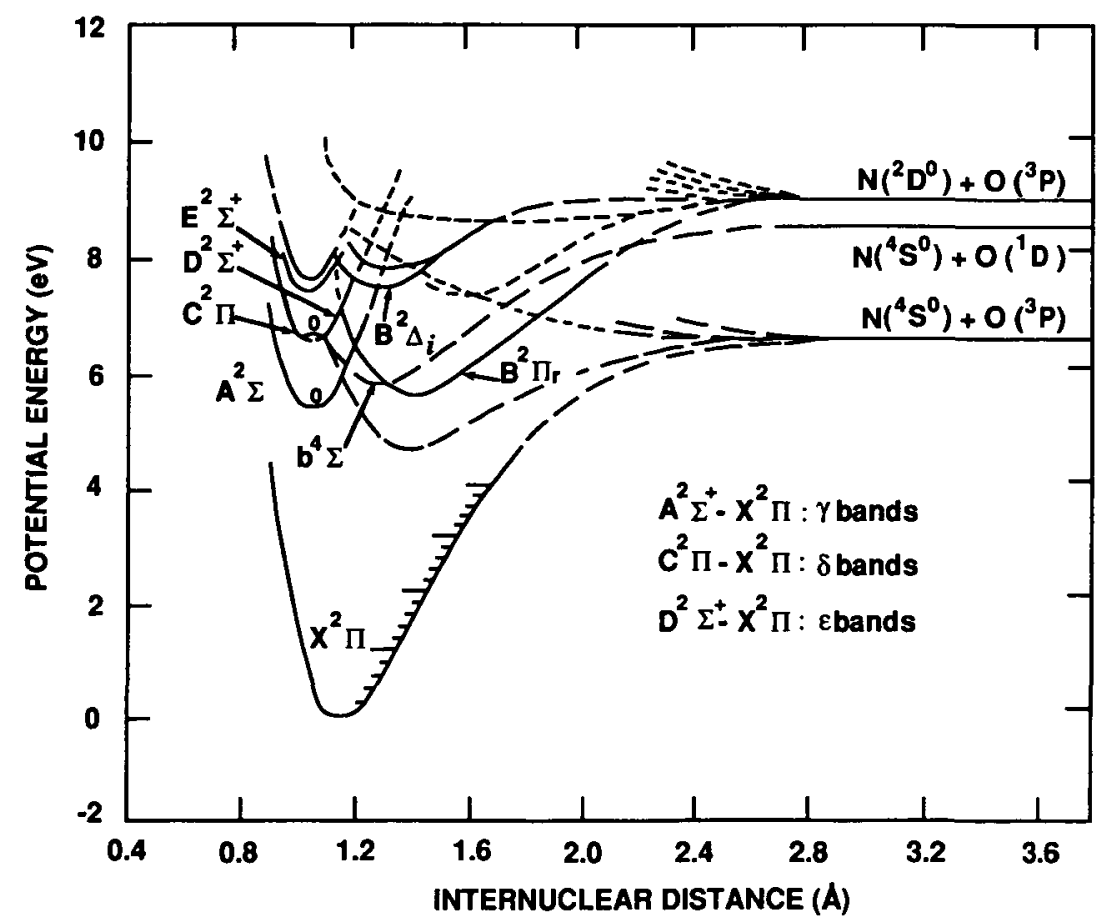

Figure 3. Simplified potential diagram for NO. (Modified from Gilmore [1986].) 
Table 5. Photochemical Sources and Sinks of NO

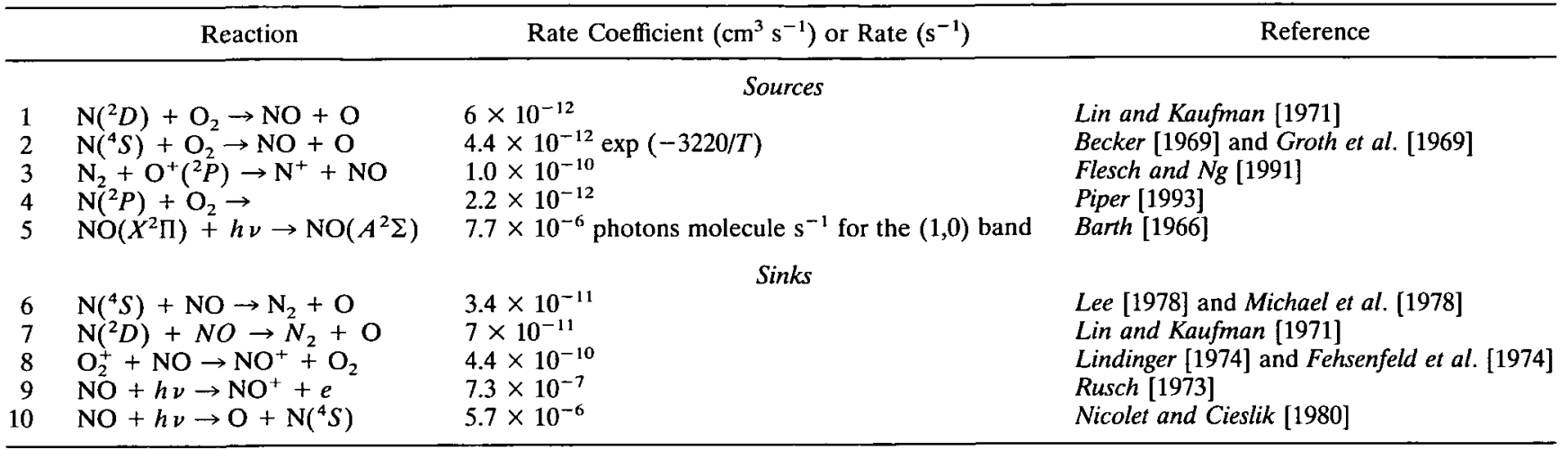
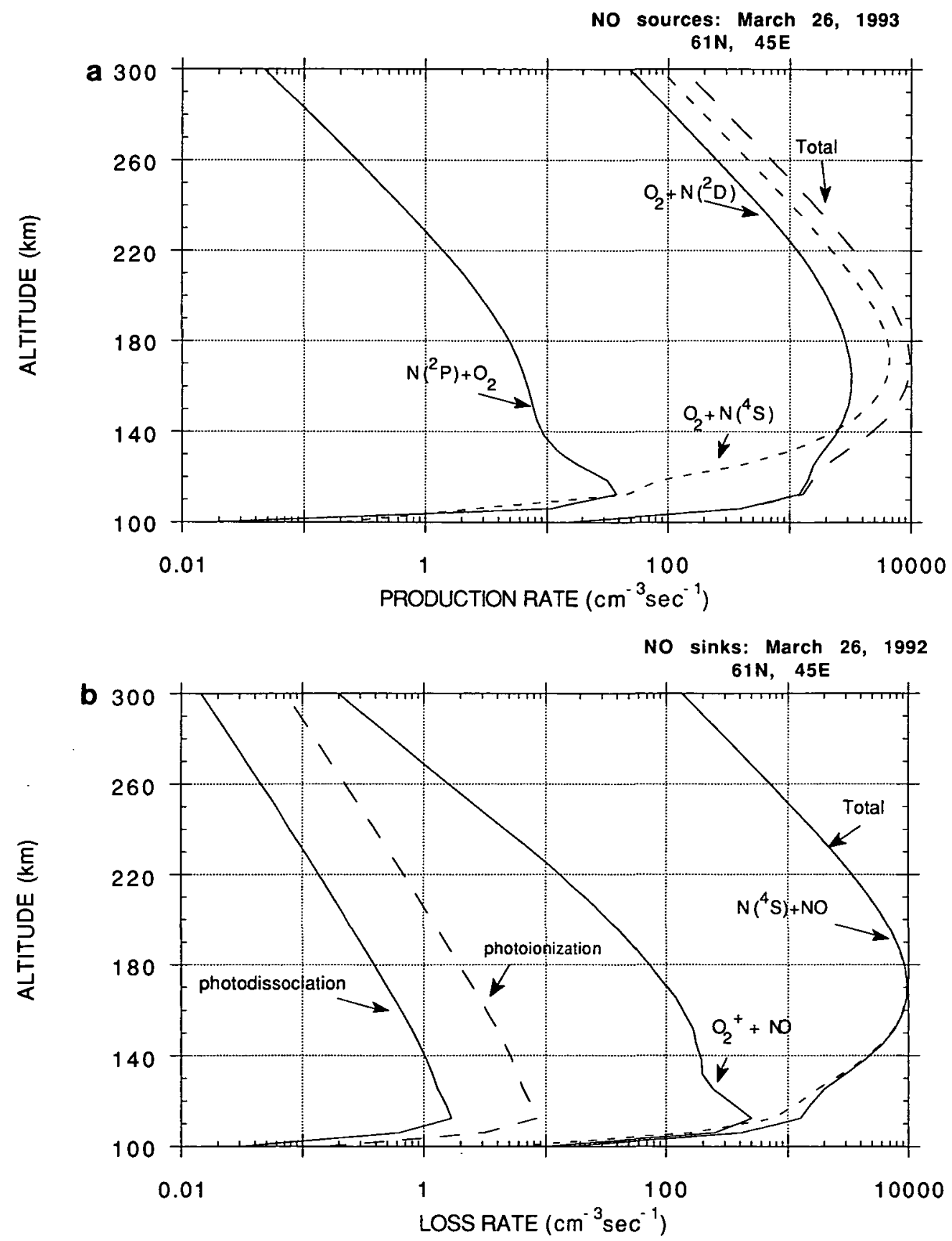

Figure 4. Photochemical (a) sources and (b) sinks of $N O A^{2} \Pi$ for a field line at $61^{\circ} \mathrm{N}, 46^{\circ} \mathrm{E}$ on March 26 , 1992, at 0730 UT. 
simultaneously acquired two-dimensional image with spectral information in one dimension and spatial information in the other, without scanning a grating or mirror to build up this image in a time series.

The spectrometer array was mounted in the payload bay of the shuttle and made observations in a variety of vehicle attitudes. Observations made with the vehicle in three different attitudes are used in this study. In the first of these (Figure 1); the nose of the vehicle was pitched down so that the field of view was directed at a tangent ray height of approximately 140 $\mathrm{km}$ and held at close to this altitude while six spectral scans were made of the full wavelength range of the instrument. These spectra are used here to illustrate the dayglow spectrum in the lower thermosphere. In the second attitude selected for this study, the vehicle was rolled about the nose-tail axis so that the field of view of the instrument was scanned down through the atmosphere while the shuttle moved along its orbital path. These data are compared with other observations and a photochemical model of the thermospheric nitric oxide. The third vehicle attitude was similar to the first, with the nose of the vehicle pitched down so that the field of view was directed into the lower thermosphere at approximately $99 \mathrm{~km}$ and held there while the shuttle moved along its orbit. In this configuration (also that illustrated in Figure 1) the grating was cycled between six of the grating steps to emphasize the major spectral features at higher time resolution than if a complete spectral scan had been done. These data will be used to illustrate the imaging capability. The geographical location of the tangent ray point in these various observation sequences is shown in Figure 2.

The geophysical parameters for the sequences used in this study are shown in Table 2 .

In the case of the March 25, 1992, column shown in Table 2, the numbers in parentheses are for the particular location of the data segment shown in this paper.

\section{Airglow Model}

The data from the roll sequence are compared with the column concentration of NO along the same line of sight computed from our interhemispherically coupled airglow model. This model, which has been described elsewhere [Torr et al., 1990], solves the time dependent continuity, momentum, energy, and photoelectron equations as a function of altitude, latitude, and longitude. The equations are solved along the magnetic field line at each grid point, from $80 \mathrm{~km}$ in one hemisphere to $80 \mathrm{~km}$ in the other hemisphere, avoiding the need for upper boundary conditions. Since the Torr et al. [1990] study, some upgrades have been made to the model and some rate coefficients have been changed. To avoid listing just the changes and requiring the reader to refer to the earlier papers, we list the entire photochemical scheme in Table 3. It also allows us to correct typographical errors that appeared in (25), (38), and (43) of Table 1 of Torr et al. [1990].

For modeling the daytime thermosphere, the three most important input parameters to the model are the solar EUV and FUV flux spectrum, the photoionization cross sections, and the total electron impact cross sections. For computing photoelectron impact ionization, the solar flux below $310 \AA$ is needed; for computing photoionization, the solar flux below $1025 \AA$ is needed; and, in computing photodissociation of $\mathrm{O}_{2}$, the solar flux in the Schumann-Runge continuum (1250-1750 $\AA$ ) is needed. Since the Spacelab 1 mission flew at a time of
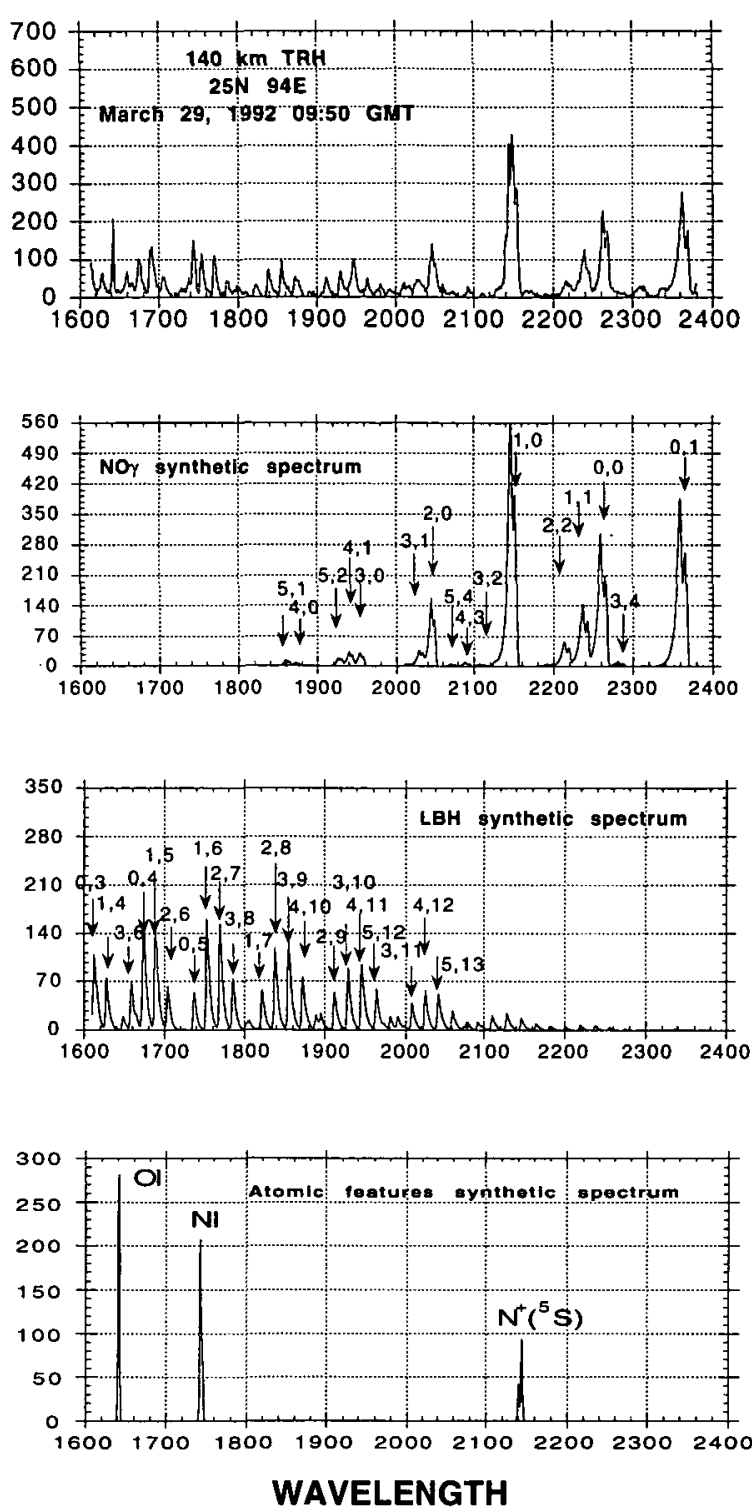

Figure 5. Segment of measured spectral sequence during which the field of view of the instrument was directed at a tangent ray height of approximately $140 \mathrm{~km}$. Also shown are the synthetically modeled components of the spectrum (the individual NO $\gamma$ and $\mathrm{N}_{2} \mathrm{LBH}$ band systems and principal atomic lines).

relatively low solar activity, the solar flux model used for that case is based on the F74113 Hinteregger reference spectrum from Torr et al. [1979], with the fluxes doubled below $250 \AA$ [Richards and Torr, 1984]. Uncertainties in the solar EUV fluxes have recently been discussed by Richards et al. [1994], who developed a new solar EUV flux model (EUVAC). The EUVAC model also uses the F74113 solar flux reference spectrum but uses the Atmosphere Explorer E measured relative variations for the solar activity scaling. The basic difference is that the old model uses only the daily $F_{10.7}$ index for scaling whereas the new model also uses the 81 -day average $F_{10.7}$ index. For the period of the Spacelab 1 mission, there is a negligible difference between the solar EUV fluxes from the two models. For higher levels of solar activity, such as prevailed at the time of the ATLAS 1 mission, the flux is scaled in each of 37 wavelength intervals according to Torr et al. [1985]. 

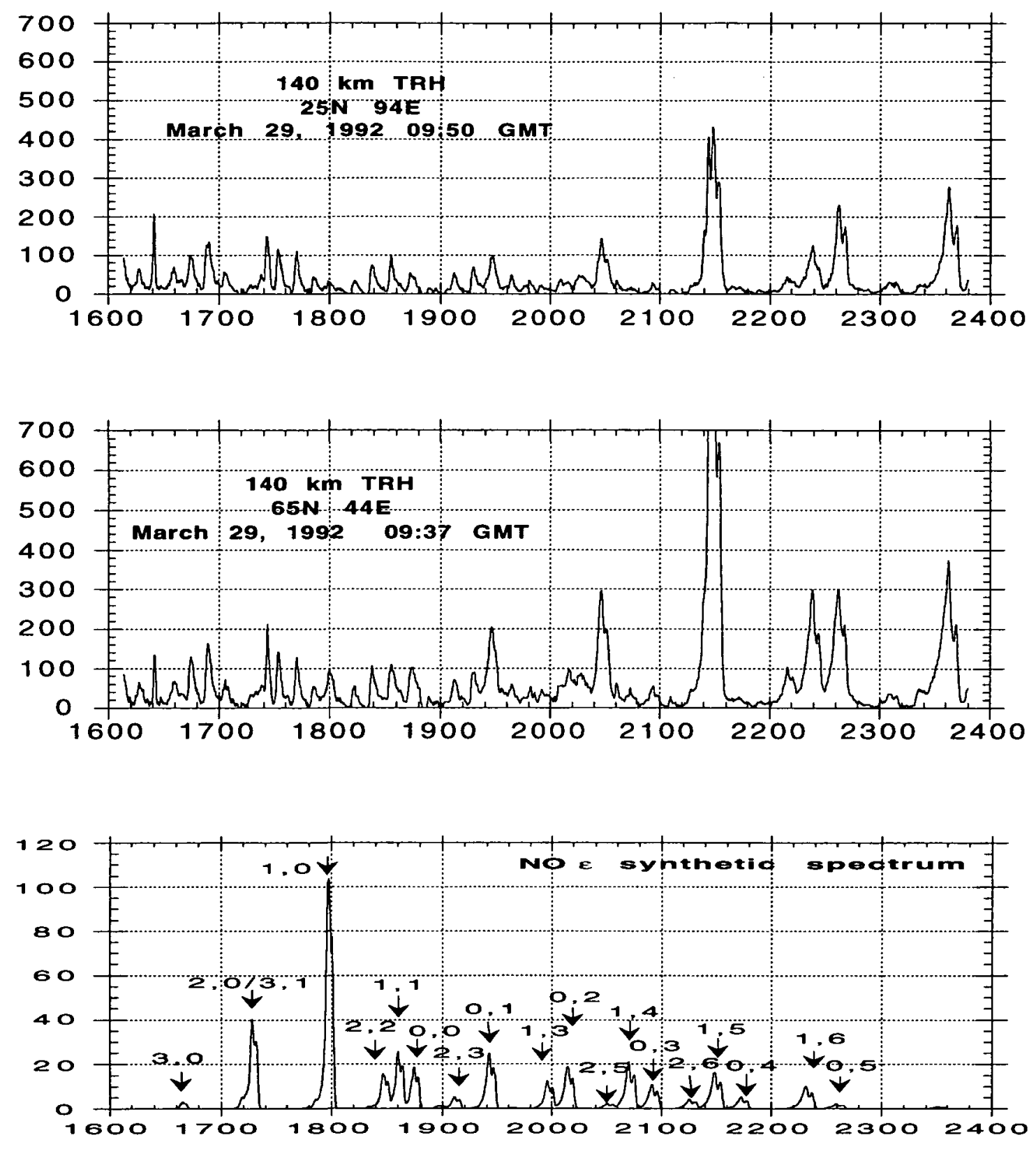

WAVELENGTH (A)

Figure 6. Comparison of the spectral segment taken at $25^{\circ} \mathrm{N}$ with one at $65^{\circ} \mathrm{N}$. The solar zenith angles in the two cases differ by less than $3^{\circ}$. Also shown are the synthetically modeled NO $\varepsilon$ bands.

The $\mathrm{O}_{2}$ dissociation frequency is determined according to Torr et al. [1980a]. The photoionization cross sections and the photoelectron impact cross sections are presented by Richards and Torr [1988, 1990] and Fennelly et al. [1992]. In summary (Table 4), the photoionization cross sections are best known; the electron impact cross sections are well known; and the total excitation cross sections are uncertain by a factor of 2 . The calculated flux is inversely proportional to the total impact cross section.

A comparison of measured and modeled photoelectron spectra using the two different EUV reference spectra (F74113 and SC\#21REFW), with the lower excitation cross sections in the case of the former, and the higher cross sections [Strickland and Anderson, 1983] in the case of the latter, is shown by Richards and Torr [1988].

The neutral atmosphere is provided to the field line interhemispheric plasma (FLIP) model from the MSIS-86 model [Hedin, 1987]. When the airglow model is run for a particular day, with the appropriate solar flux and magnetic indices, the output provides a four-dimensional array (altitude, latitude, longitude, local time) through which the line of sight of the instrument can be projected, and the slant path intensity computed for any point along the orbit. Studies comparing the ISO observations of emissions from other atmospheric constituents obtained on the ATLAS 1 mission with the FLIP model have been reported elsewhere [Torr et al., 1994, 1993a, b). 


\section{Photochemical Sources and Sinks of Nitric Oxide in the Thermosphere}

A potential term diagram for $\mathrm{NO}$ is shown in Figure 3 (which is simplified from Gilmore [1986]). The $\gamma$ bands arise from transitions from the $A^{2} \Sigma$ state to the $X^{2} \Pi$ state. The $A$ state can be populated by various mechanisms, including resonance fluorescence of sunlight, cascade from higher levels, and photochemical sources. The $(1,0)$ band is particularly bright in the dayglow because of its high-fluorescence efficiency [Callear and Smith, 1963]. Photochemical reactions are responsible for the removal of NO in addition to photoionization and photodissociation. Because the first ionization potential of NO is relatively low $(9.25 \mathrm{eV})$, it is the only important atmospheric constituent that is ionized by the strong Lyman $\alpha$ emission in sunlight (a fact already referred to above as the major source of the $D$ region ionization).

The first measurements of the NO $\gamma$ bands [Barth, 1964] yielded NO concentrations 2 orders of magnitude larger than those predicted by simple resonance fluorescence of sunlight [Barth, 1961]. In an attempt to bring the theory into better agreement with the measurements, Nicolet [1965a, b] introduced ionic reactions. Norton and Barth [1970] subsequently added a source of NO resulting from the interaction of $\mathrm{N}\left({ }^{2} D\right)$ with $\mathrm{O}_{2}$ and were able to obtain relatively good agreement in the magnitude of the concentrations. Lower-altitude measurements were then made by Meira [1971], and these required the development of models incorporating diffusive transport [Rusch, 1973] which were able to account for the shape at the lower altitudes. More recently, Siskind et al. [1990] have sug-

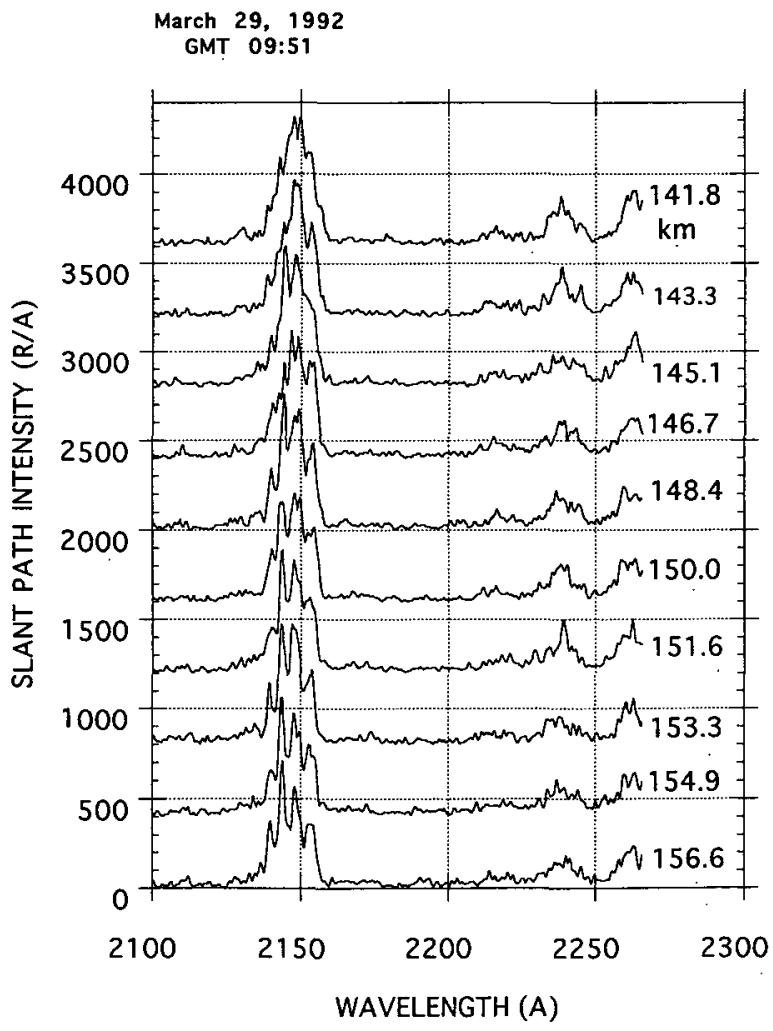

Figure 7. Example of spectral/altitude image. These are the same data shown in Figure 5 but with the altitude dimension shown resolved.
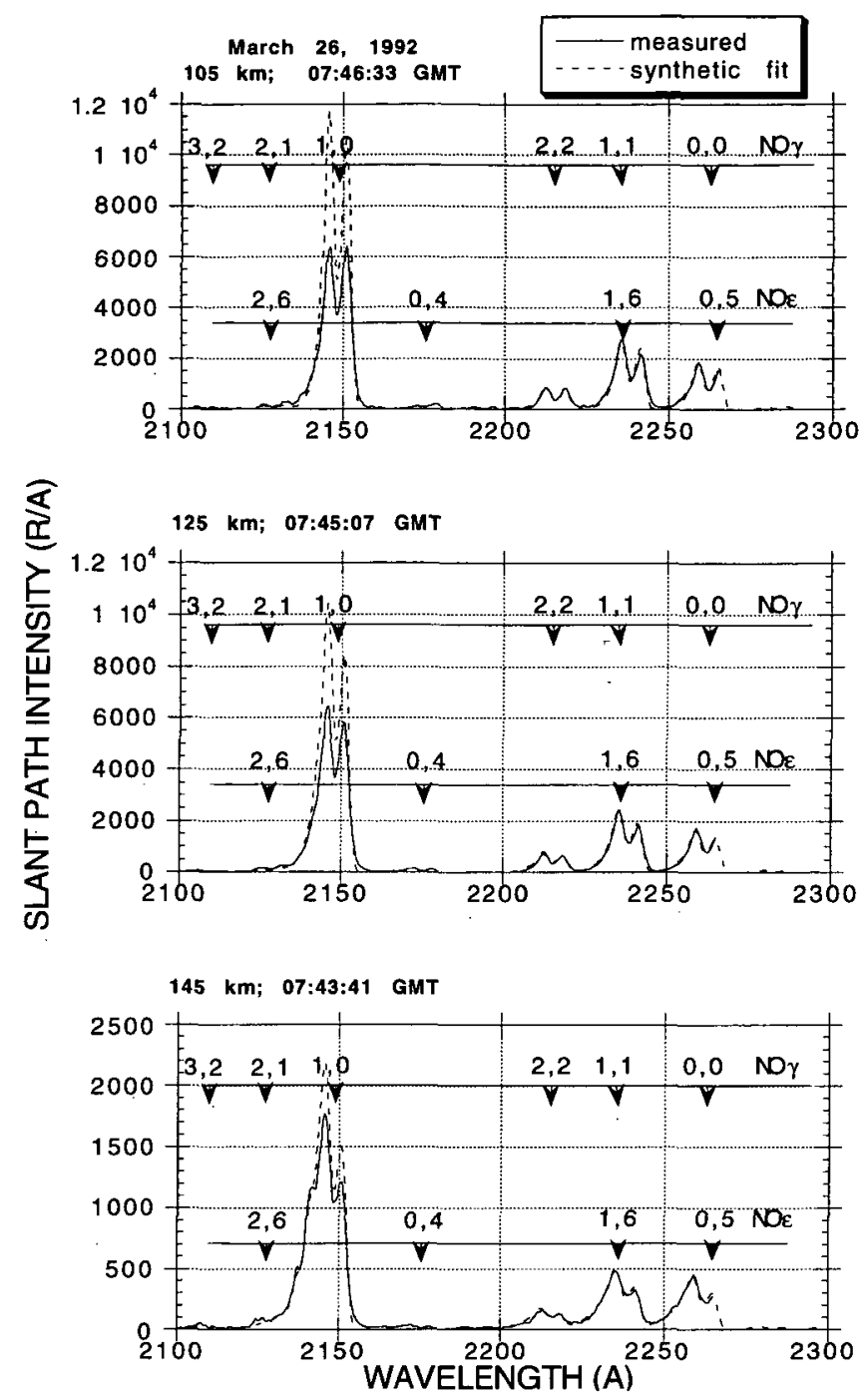

Figure 8. Measured spectrum at selected tangent ray heights as field of view is rolled down through the atmosphere. Also shown is the synthetic spectral fit to each spectral segment.

gested that solar soft $\mathrm{X}$ rays produce $\mathrm{N}_{2}^{+}$which then in turn produces $\mathrm{N}\left({ }^{2} D\right)$ and hence NO.

The present photochemical scheme for the production of NO in the thermosphere is given in Table 5.

In Figure 4 we show the major photochemical sources and sinks of the $A^{2} \Sigma$ state of NO for conditions appropriate to the March 26, 1993 roll sequence listed in Table 2 above. These calculations are for $61^{\circ} \mathrm{N}, 46^{\circ} \mathrm{E}$. Over the entire altitude range of interest here, the major sources are the reactions of $\mathrm{N}\left({ }^{2} D\right)$ and $\mathrm{N}^{4} S$ ) with $\mathrm{O}_{2}$, and the principal loss mechanism is the reaction of $\mathrm{N}\left({ }^{4} S\right)$ with $\mathrm{NO}$, with a small contribution from the charge exchange reaction with $\mathrm{O}_{2}^{+}$near $110 \mathrm{~km}$.

At high latitudes the long photochemical lifetime of NO makes it an important candidate for transport to lower altitudes where it becomes involved in the catalytic removal of ozone ( $\mathrm{NO}+\mathrm{O}_{3} \rightarrow \mathrm{NO}_{2}+\mathrm{O}_{2}$ and $\mathrm{NO}_{2}+\mathrm{O} \rightarrow \mathrm{NO}+\mathrm{O}_{2}$ ).

\section{Spectral Images at $140 \mathrm{~km}$ Tangent Ray Height}

Figure 5 shows a spectral segment obtained on day 89, 1992 (March 29) at 0950 UT. The configuration for this (illustrated 


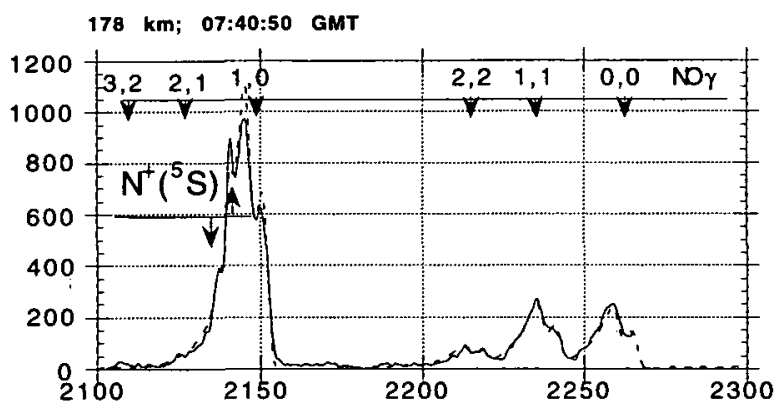

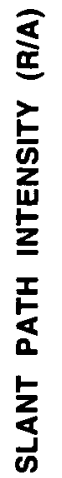
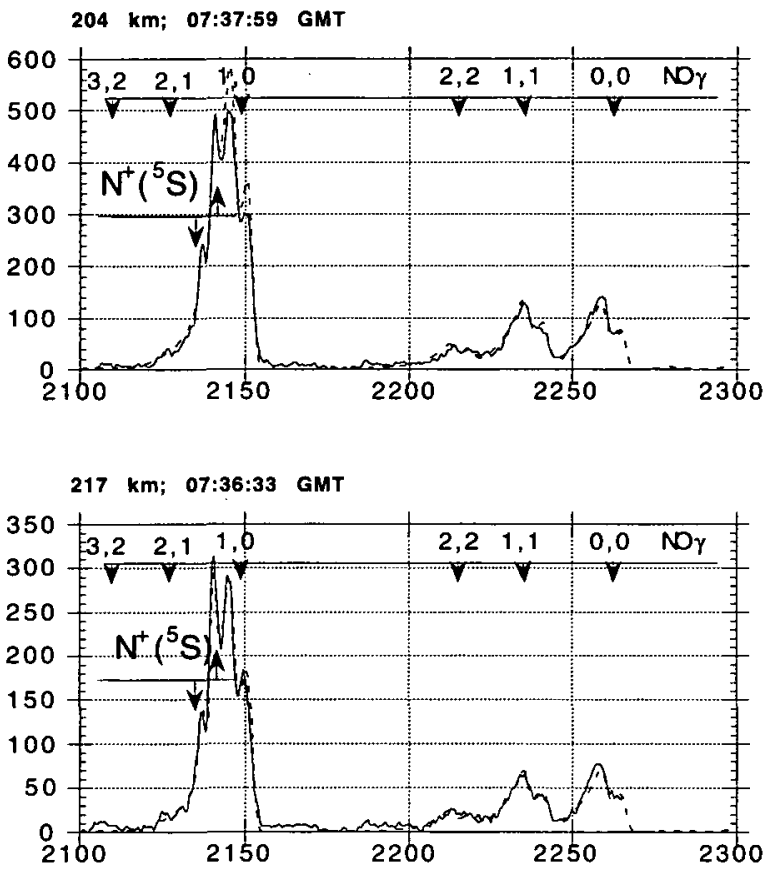

Figure 8. (continued)

in Figure 1) was discussed in section 2 (nose of the orbiter pitched down so that the line of sight pointed at a nearly fixed tangent ray height (TRH) of approximately $140 \mathrm{~km}$ ). During this sequence the full spectral range of the instrument was scanned 6 times, obtaining representative spectra covering latitudes from the equator to almost $60^{\circ} \mathrm{N}$ (Figure 2). The data shown in Figure 5 are taken at $25^{\circ} \mathrm{N}$. The lower panels in Figure 5 show the synthetic spectra for the various systems in this portion of the spectrum (NO $\gamma, \mathrm{N}_{2}$ Lyman-Birge-Hopfield (LBH) and the major atomic features). The synthetic spectra have been generated using the line-by-line code of Arnold et al. [1969].

As can be seen from Figure 5, the dayglow spectrum in the lower thermosphere in this wavelength window is dominated by NO $\gamma$ and $\mathrm{N}_{2}$ LBH bands. Figure 6 shows a comparison of the low-latitude spectrum of Figure 5 with the higher-latitude spectrum of this sequence taken at $65^{\circ} \mathrm{N}$. The two are quite similar as far as the LBH bands are concerned. The NO $\gamma$ bands are significantly $(>2 \times)$ brighter in the higher-latitude case. Also, the $\mathrm{NO}_{\varepsilon}$ bands are clearly present in the higherlatitude spectrum, even at these altitudes, as can be seen at the locations of the $(1,0)$ and $(3,1) \varepsilon$ bands. In the sections below we shall discuss further the contributions by the NO $\varepsilon$ bands and the NO $\delta$ bands. The overlaying of the synthetic spectral fit to the observations in the FUV has been shown by Torr et al. [1994].

The data shown in Figure 5 are averaged across the 10 altitude segments of the image. In Figure 7 we show a portion of this spectrum in which the adjacent altitude elements are resolved. The changing characteristic of the spectrum in this simultaneously acquired image is evident. The adjacent rows in the spectrum each represent $1.7 \mathrm{~km}$ of altitude, so that the full image spans 129.8 to $145.4 \mathrm{~km}$. The $\mathrm{N}^{+}\left({ }^{5} \mathrm{~S}\right)$ atomic doublet at 2139.7/2143.6 $\AA$, which overlaps the left branch of the NO $\gamma$ $(1,0)$ band, can be seen to decrease in intensity with decreasing altitude in this altitude range.

The temperature characteristics of these spectral features are discussed further in section 6 .

\section{Altitude Variation of NO Concentration and Temperature in the Thermosphere}

The data sets used here are those acquired in the vehicle roll maneuvers in which the crew first positioned the orbiter in such
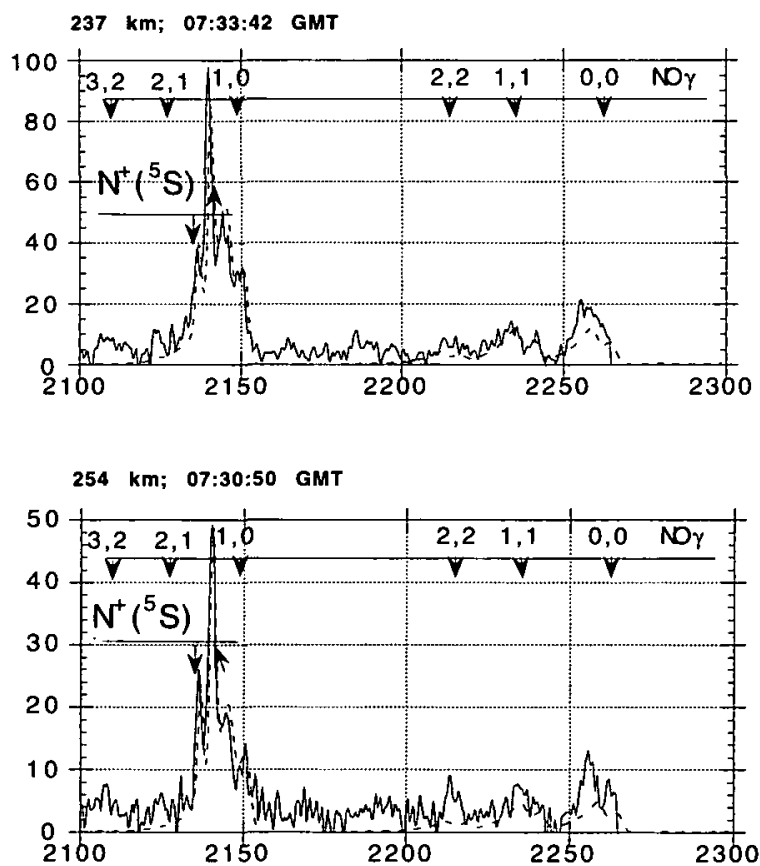

$269 \mathrm{~km} ; 07: 27: 59$ GMT

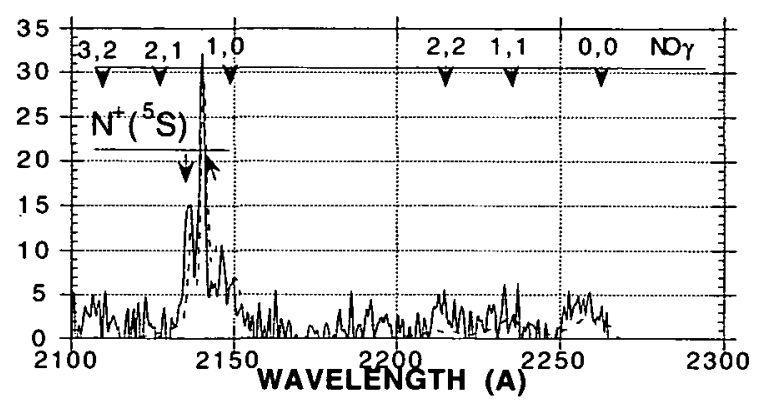

Figure 8. (continued) 


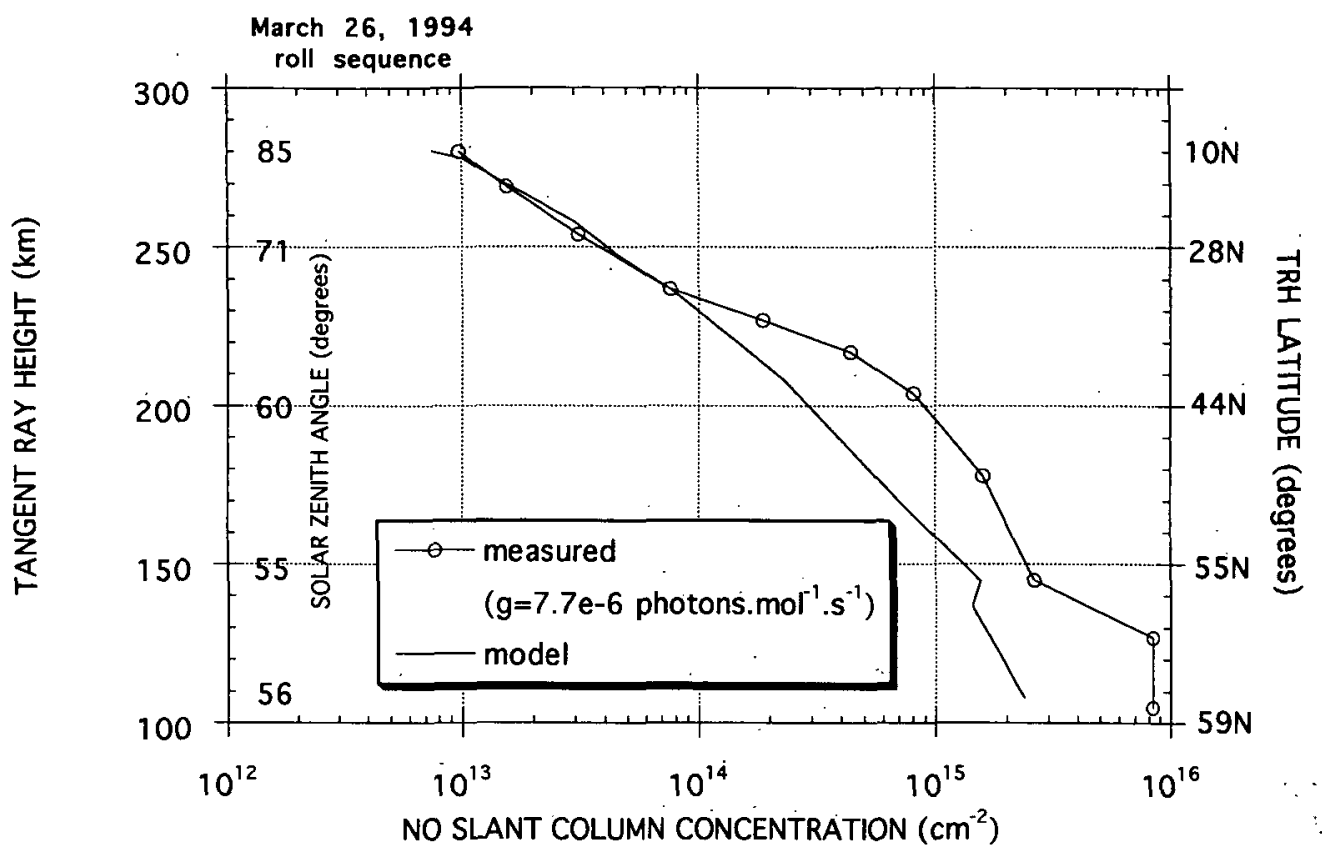

Figure 9. Comparison of column concentration of NO derived from the data shown in Figure 8 with that computed from the global airglow model.

a way that the instrument line of sight was tangential to the orbit altitude of $300 \mathrm{~km}$. The direction of the line of sight was back along the orbit, into the wake. The shuttle was then rolled at a controlled rate to scan the narrow dimen- sion of the field of view $\left(0.007^{\circ}\right)$ down through the atmosphere. In the course of this observing sequence, the wavelength was cycled between six selected grating steps in each of the spectrometers, rather than executing complete wavelength scans

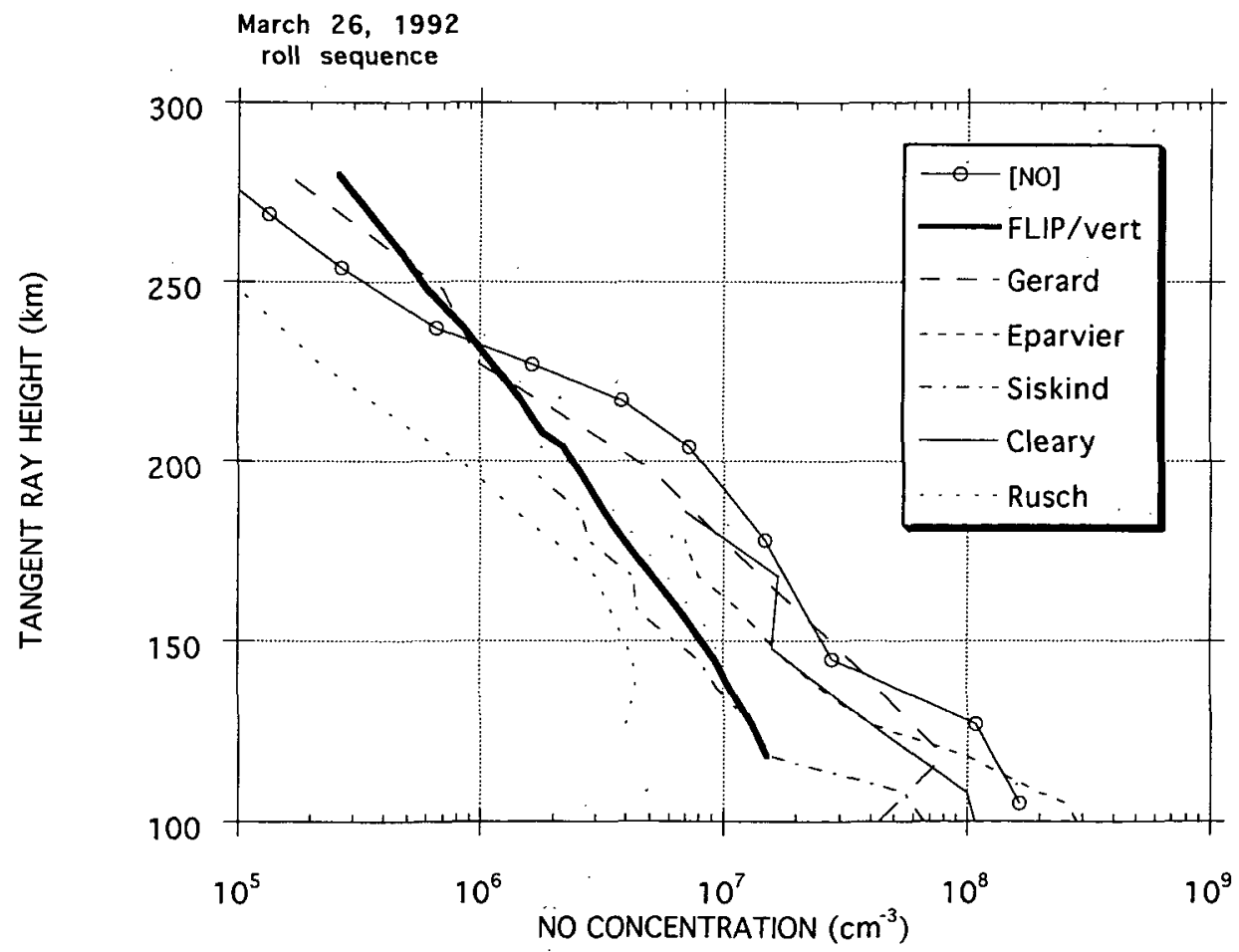

Figure 10. NO concentrations derived from the column concentrations inferred from the measured slant path intensities. Shown for comparison are the concentrations from the FLIP model, as well as various measured vertical NO profiles [Rusch, 1973; Gerard, 1984; Cleary, 1986; Siskind et al., 1990; Eparvier et al., 1992]. 

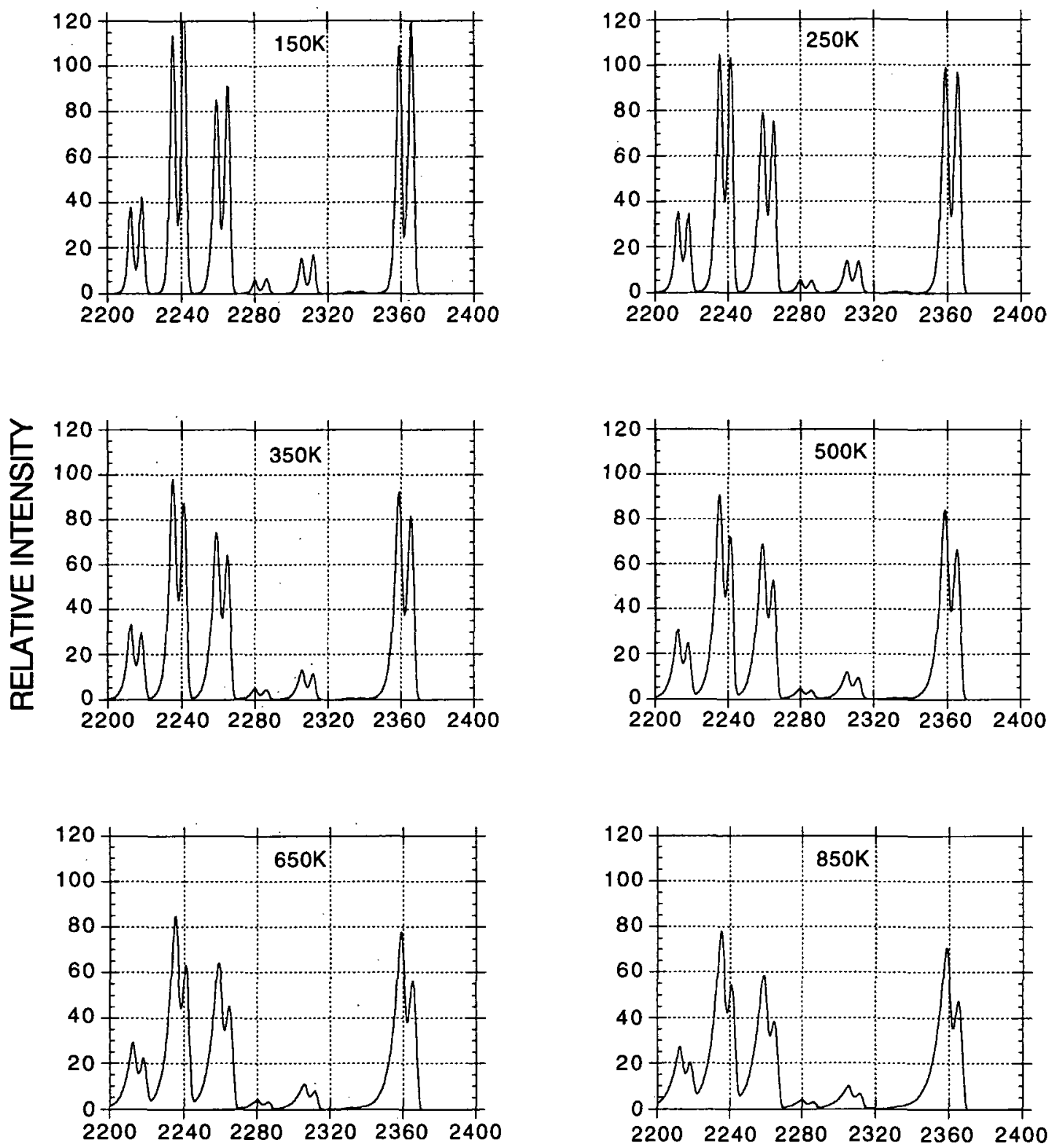

\section{WAVELENGTH (A)}

Figure 11. Illustration of the sensitivity of the relative magnitudes of the $P$ and $R$ branches of several NO $\gamma$ bands to temperature.

over the entire range accessible to the instrument. During the course of one of these rolls, the ground track of the vehicle covered almost a quarter of an orbit: The latitude/longitude covered is illustrated in Figure 2. Parameters such as date, local time, solar zenith angle and magnetic activity are shown in Table 2.

Figure $8 \mathrm{a}-8 \mathrm{j}$ shows the spectral segment from 2090 to 2270 $\AA$ (a simultaneously acquired spectral image) at the various tangent ray heights at which the measurements were made. Also shown in the figure is the synthetic fit to the spectrum at each altitude. Included in the spectral fit are the NO $\gamma$ bands and $\mathrm{N}^{+}\left({ }^{5} S\right)$ atomic features. The principal features are labeled. In addition to these, bands from the NO $\varepsilon$ system can be seen at the lower altitudes.

The self-absorption of the $(1,0)$ band at $105 \mathrm{~km}$ is evident in the fact that the synthetic spectrum is much larger than the measurements for this band, while the $(1,1)$ band is well fitted. The self-absorption can be seen up to approximately $200 \mathrm{~km}$. Above $200 \mathrm{~km}$, a good fit is obtained to the $(1,0)$ band. By 145 $\mathrm{km}$ the $\mathrm{N}^{+}\left({ }^{5} S\right)$ doublet, which lies on the left hand branch of the $\gamma(1,0)$ band, starts to become evident. The two lines of the doublet at 2139 and $2143 \AA$ are clearly resolved. By $269 \mathrm{~km}$, this is the dominant feature in this portion of the spectrum. We return to the $\mathrm{N}^{+}\left({ }^{5} S\right)$ feature below.

Two parameters can be derived from the spectral fits to the NO $\gamma$ bands shown in Figure 8. The first is the column concentration of NO. The second is the effective NO temperature along the line of sight.

Column concentration: From the data measured in this sequence we can determine the total column concentration of NO along the line of sight at each point along the orbit and obtain an altitude/latitude profile. For example, using the $(1,1)$ band, the 
March 26, 1992

roll sequence

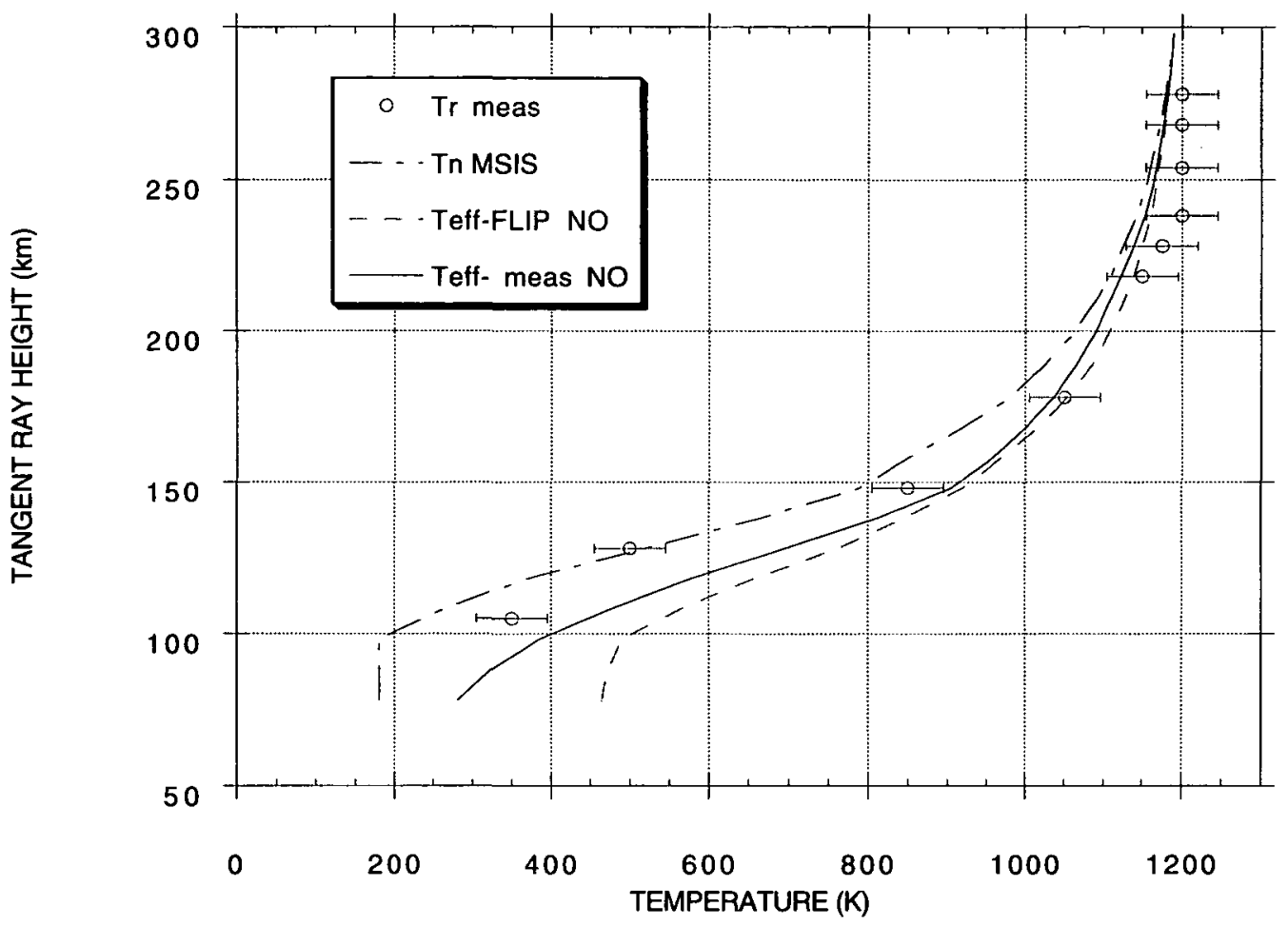

Figure 12. Comparison of temperatures derived from the synthetic spectral fit to the data shown in Figure 8 with the neutral temperature given by MSIS- 86 at each tangent ray height (TRH), and the computed effective temperature that would be seen looking along this line of sight.

column concentration of nitric oxide is obtained by using the resonance fluorescence $g$ factor for the $(1,1)$ band as follows:

$[\mathrm{NO}]_{\mathrm{col}}=I($ Rayleighs $) \times 1 \times 10^{6} / g_{1,1}$ molecules $/ \mathrm{cm}^{2}$

where $I$ is the measured intensity of the $(1,1)$ band in Rayleighs and the factor of $10^{6}$ converts from Rayleighs to photons per

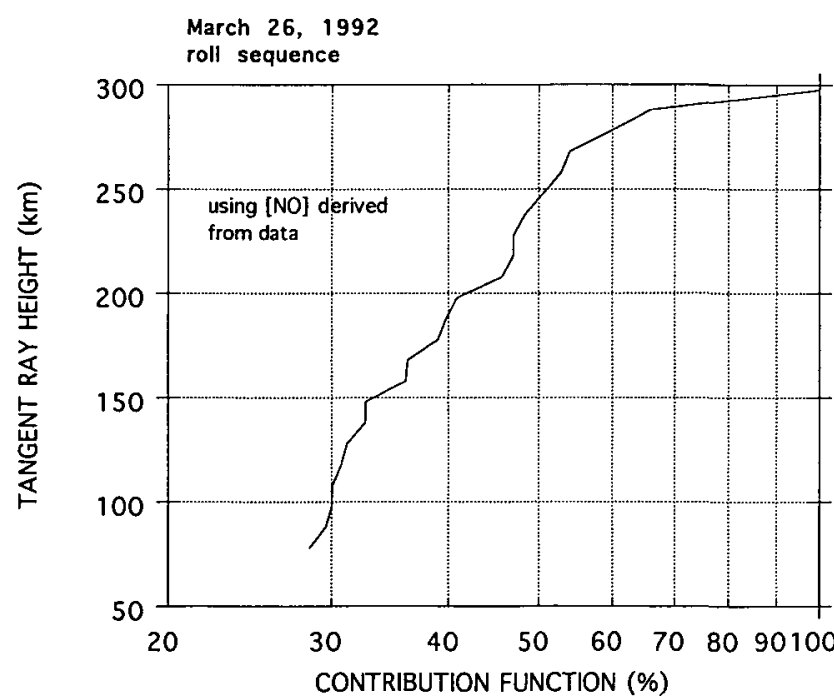

Figure 13. NO contribution function as a function of altitude for the concentration profile derived from these dayglow measurements and shown in Figure 10. second. We have used the value of $2.1 \times 10^{-6}$ photons molecule ${ }^{-1} \mathrm{~s}^{-1}$ for the $g$ factor of the $(1,1)$ band, and $7.7 \times 10^{-6}$ for the $(1,0)$ band [Barth, 1965].

The results are shown in Figure 9 with the column concen-

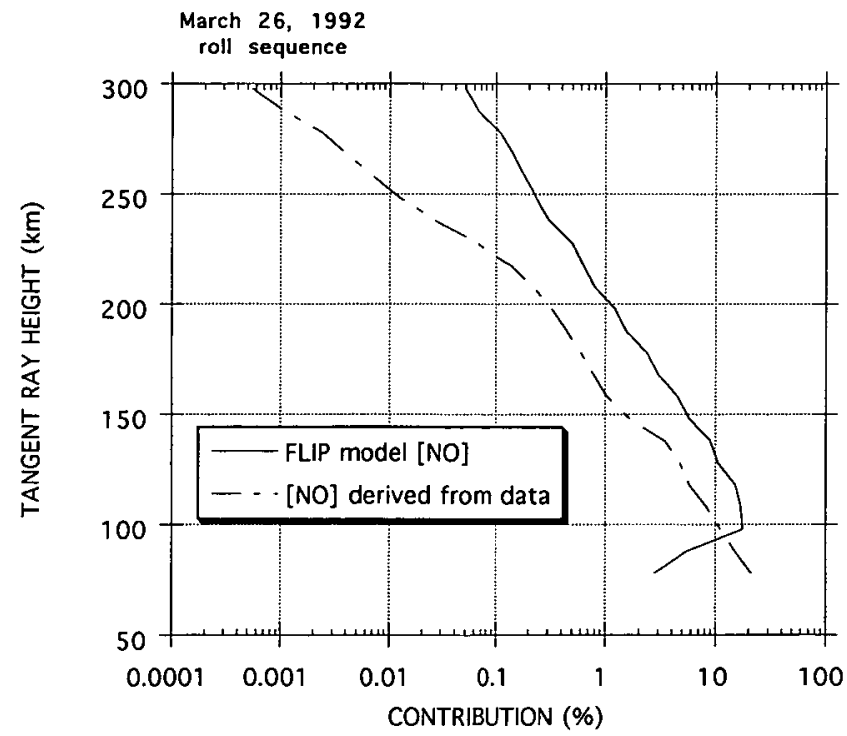

Figure 14. Contribution to the signal measured at a TRH of $80 \mathrm{~km}$ from each $10 \mathrm{~km}$ layer between $80 \mathrm{~km}$ and $300 \mathrm{~km}$. The full line curve is computed using the FLIP model [NO] and the dashed curve is that using the [NO] inferred from these data. 


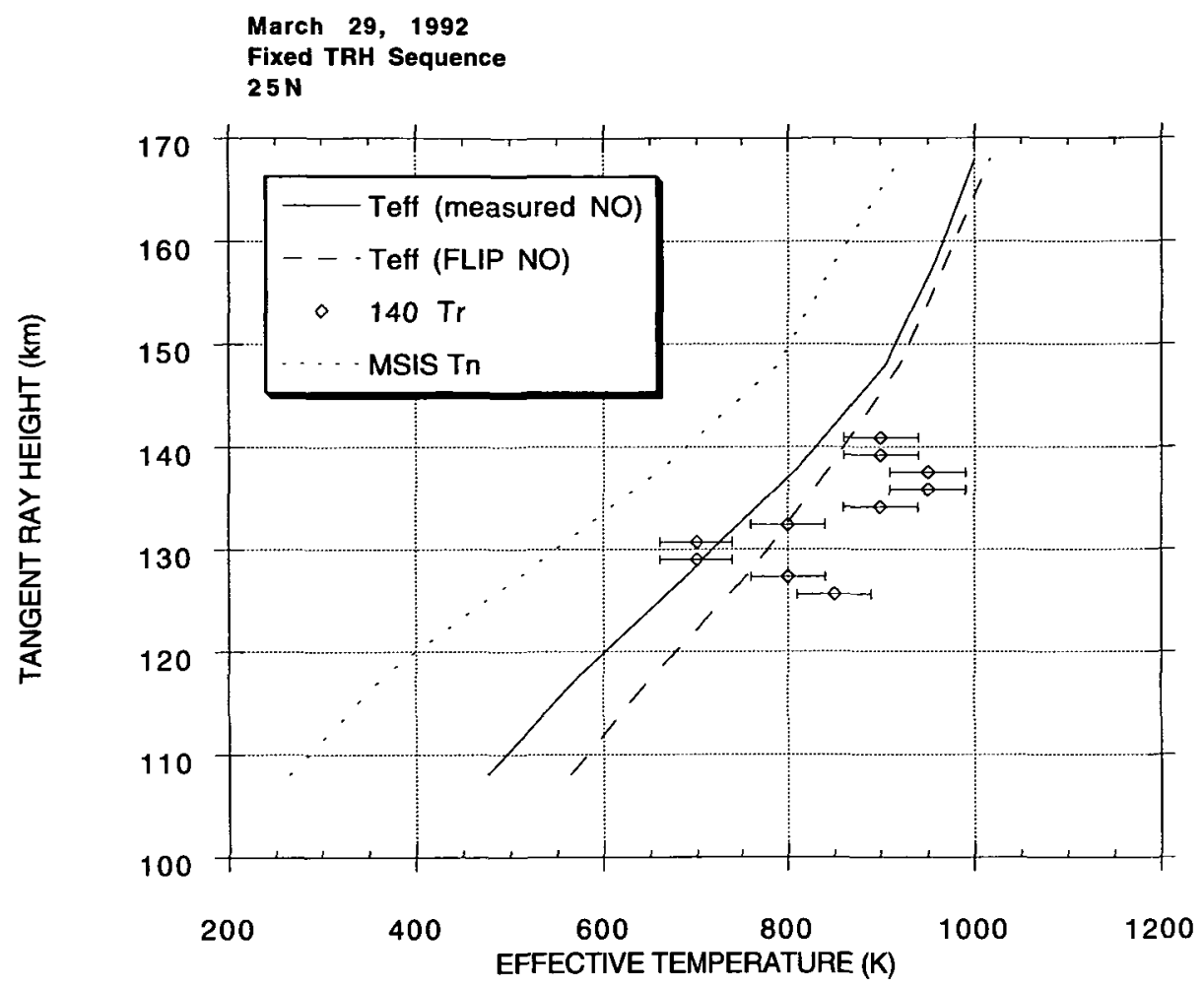

Figure 15. Temperature altitude image obtained with the center of the field of view directed at approximately $140 \mathrm{~km}$, with the computed effective temperature shown for comparison.

trations predicted by our interhemispherically coupled airglow model for comparison. The model is found to agree well with the data above $\sim 230 \mathrm{~km}$ (which corresponds to lower latitudes), but below this the model predicts less column abundance of NO than is obtained from the dayglow measurements by a factor of $2-3$. Figure 10 shows the NO concentration profile derived from the column concentration profile of Figure 9 (using the very simple spherical layer inversion technique), with various other measurements and our FLIP model shown for comparison. Bearing in mind that the profile measured from ATLAS 1 is one that covers quite a range of latitude, while the earlier measurements are strictly vertical profiles, the present results lie on the high side of the six profiles shown for comparison. However, [NO] is known to exhibit great variability with solar and geomagnetic activity and with latitude. The ISO inferred concentrations also fall off less steeply with height than does our model.

Temperature: The shape and relative size of the $P$ and $R$ branches of the $\gamma$ bands are dependent on the NO temperature, and hence the neutral temperature. This is illustrated in Figure 11 in which we show a number of these bands modeled for a range of thermospheric/mesospheric temperatures from 150 to $850 \mathrm{~K}$. By fitting the bands shown in Figure 8, we obtain the temperatures shown in Figure 12. This approach was used by Erwin [1985] and also Bosserman [1989] to determine NO temperatures using the data obtained with the ISO during the Spacelab 1 mission. Subsequently, the approach was used by Barth and Eparvier [1993] to obtain temperatures from a highlatitude, daytime rocket experiment. We have fitted the $(1,0)$ band above $150 \mathrm{~km}$ and the $(1,1)$ band at the lower altitudes. Above $150 \mathrm{~km}$, the self-absorption of the $(1,0)$ band is small and this band has the advantage of considerably brighter in- tensity. In the region of overlap, these two bands agree in temperature. Also shown in Figure 12 is the neutral temperature at the tangent ray height from the MSIS- 86 model. However, as is the case with the column concentrations, the measurement is an integral of all the NO along the line of sight, and may not be well represented by the temperature at the tangent point itself, even though the [NO] is falling steeply with altitude. In other words, we need to estimate the extent to which this temperature fit is modified by the emission from the higher (hotter) altitudes along the line of sight. To do this we have computed the contribution function from each $10 \mathrm{~km}$ layer between the shuttle altitude of $300 \mathrm{~km}$ and the tangent ray height. The results are shown in Figure 13. When looking at a TRH of $100 \mathrm{~km}$, for example, $30 \%$ of the NO in the line of sight is in the $10 \mathrm{~km}$ wide layer centered at $100 \mathrm{~km}$. The remaining $70 \%$ is from higher altitudes. When looking at a TRH closer to the shuttle altitude, say $250 \mathrm{~km}$, a larger percentage $(50 \%)$ is from the region of interest. Figure 14 shows the contribution to the measured signal when looking at a TRH of $80 \mathrm{~km}$, from each $10-\mathrm{km}$ layer between the orbital altitude and $80 \mathrm{~km}$. This function is shown for both the FLIP model $[\mathrm{NO}]$ and the $[\mathrm{NO}]$ inferred from these measurements. It can be seen from Figure 14 that the contribution of the hotter NO at higher altitudes falls off rapidly with increasing height. Using the model or measured [NO], and the temperatures at the tangent point from the MSIS-86, we can compute the effective (column) temperature at each point from:

$$
T_{\text {eff }}=\sum_{\text {TRH }}^{300} T \mathrm{n}[\mathrm{NO}] d s / \sum_{\text {TRH }}^{300}[\mathrm{NO}] d s
$$


where the shuttle is orbiting at $300 \mathrm{~km}$, and the line of sight passes through the TRH and on out to $300 \mathrm{~km}$ on the far side. This effective temperature is also shown in Figure 12. Below $\sim 130 \mathrm{~km}$, the data indicate a cooler temperature than is predicted by the model.

From Figure 12 it can be seen that near $140 \mathrm{~km}$ the neutral temperature is changing by about $200 \mathrm{~K}$ over $20 \mathrm{~km}$. Returning to the data used in section 5 , in which the length of the spectrometer entrance slit was positioned perpendicular to the horizon, a simultaneous altitude image of $17 \mathrm{~km}$ is obtained. The $0.65^{\circ}$ field of view is imaged onto 10 adjacent lines on the detector, with each line spanning $1.7 \mathrm{~km}$ at this tangent ray height. In the case of the spectra shown in Figure 5, we averaged the data across the adjacent altitude segments. In Figure 7 we showed the same spectral segment resolved into the altitude slices. By spectrally fitting each of the 10 components, we obtain a slant path temperature for each $1.7 \mathrm{~km}$ altitude segment, and these are shown in Figure 15 together with the effective temperature expected for this particular line of sight
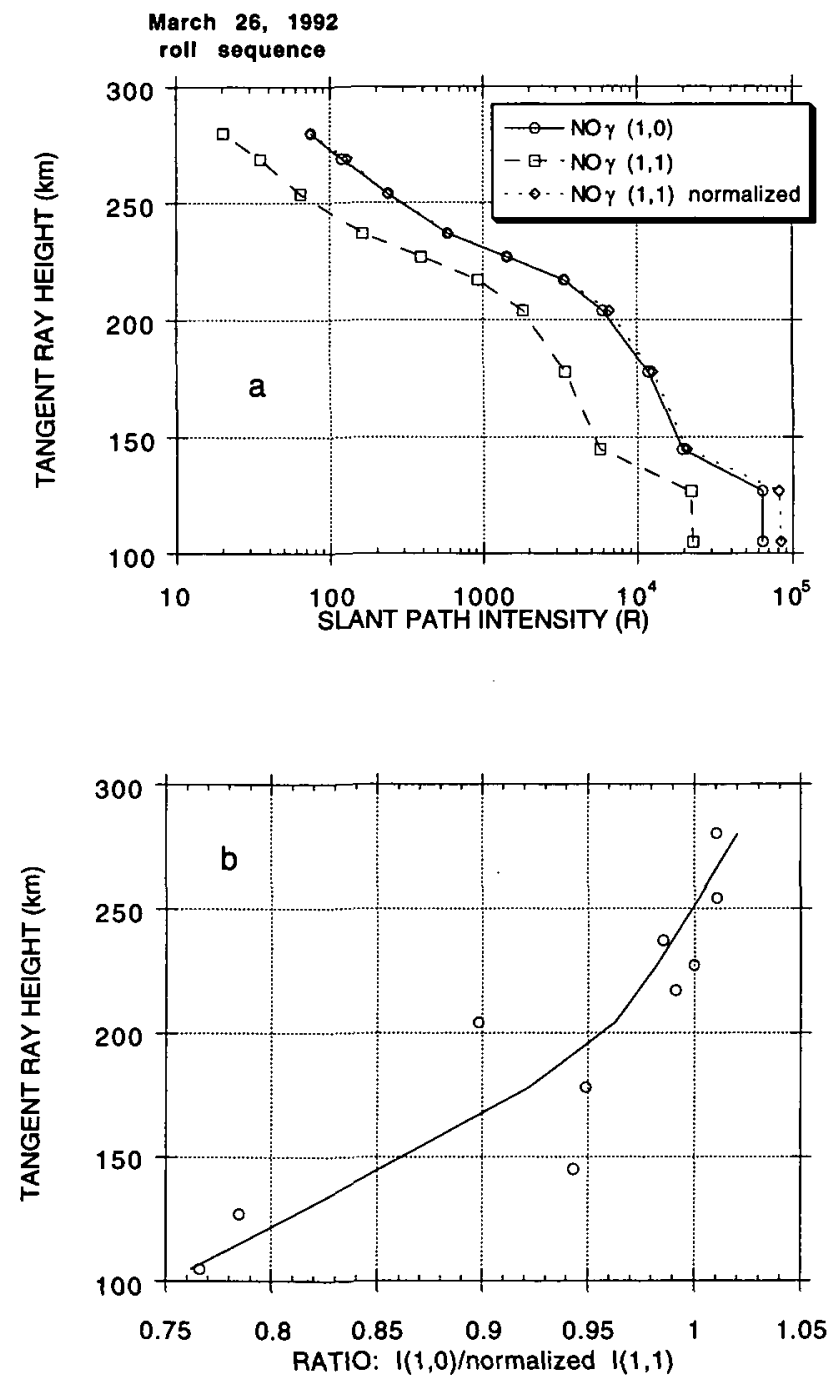

Figure 16. Illustration of the self-absorption of the NO $\gamma$ $(1,0)$ band as a function of altitude: (a) comparison of NO $\gamma$ $(1,1)$ and $(1,0)$ band slant path intensities, also showing the $(1,1)$ band normalized to the $(1,0)$ band at $220 \mathrm{~km}$; and (b) ratio of the band intensities shown in (a), with a weighted smoothed curve drawn through the ratios.
Table 6. Geophysical Parameters for Spacelab 1 Sequence

\begin{tabular}{lc}
\hline \multicolumn{1}{c}{ Parameter } & December 7,1983 \\
\hline Shuttle attitude & Fixed tangent ray height \\
& $(\sim 104 \mathrm{~km})$ \\
Local time & 1607 \\
Solar zenith angle & 84.8 \\
Latitude & $37^{\circ} \mathrm{N}$ \\
Longitude & $175^{\circ} \mathrm{E}$ \\
$\mathrm{F}_{10.7}$-cm flux & 98 \\
$A p$ & 11 \\
\hline
\end{tabular}

from the model. As in the case of the roll data discussed above, the $140 \mathrm{~km}$ TRH data indicate that the NO temperature is in reasonable agreement with the model at these altitudes.

Self-absorption: We have already discussed the fact that the $\gamma(1,0)$ band is self absorbed at the lower altitudes. In Figure 16a we show a comparison of the altitude profiles of the $(1,1)$ and the $(1,0)$ bands. In Figure 16a we also show the results of normalizing the slant path intensities of these two bands at $220 \mathrm{~km}$. While the fall off in the $(1,0)$ band below $150 \mathrm{~km}$ is evident, there is absorption (although small) indicated up to $\sim 200 \mathrm{~km}$, as was also the case in the spectral fits shown in Figure 8. In Figure 16b we show the ratio of the two normalized intensity profiles.

$\mathrm{N}^{+}\left({ }^{5} \mathrm{~S}\right)$ Doublet: A prominent feature in the spectra shown in Figure 7 at the higher altitudes is the doublet due to $\mathrm{N}^{+}\left({ }^{5} S\right)$ at $2139.7 / 2143.6 \AA$. In Figure 17 we show the intensity of this feature as a fraction of the sum of the $\mathrm{N}^{+}\left({ }^{5} S\right)$ doublet and the NO $\gamma(1,0)$ band. From Figure 17 it can be seen that the atomic doublet would contribute $\sim 10 \%$ or less of the unresolved $\mathrm{N}^{+}\left({ }^{5} S\right)$ and NO $\gamma(1,0)$ emission below $200 \mathrm{~km}$.

\section{Altitude Imaging of the Lower Thermosphere/Upper Mesosphere}

Using the same altitude imaging configuration discussed above and illustrated in Figure 1, several segments were flown during the mission with the center of the field of view directed down into the lower thermosphere and upper extent of the mesosphere. In Figure 18 we show an example of a spectral/ altitude image segment from an observation sequence taken on March 25,1992 , at $56^{\circ} \mathrm{N}, 63^{\circ} \mathrm{E}$. The ground track for the full segment is shown in Figure 2. This particular image spanned the altitude range from 93 to $107 \mathrm{~km}$ with each row on the detector corresponding to a $2 \mathrm{~km}$ altitude segment. We have derived temperatures by fitting the $(1,1)$ band, and these fits are shown in Figure 19, as compared with the anticipated effective temperature computed from our modeled NO and the MSIS neutral temperature model. Our NO model is not rigorous below $100 \mathrm{~km}$ at present because it neglects odd $\mathrm{N}$ production from photoelectrons with energies greater than 100 $\mathrm{eV}$. As a result, the computed effective temperature is a rough estimate of what we would expect to measure at the low altitudes and is shown in Figure 19 to provide a point of reference rather than a quantitative comparison. Given the uncertainties in the model, the agreement in temperature is good, and we believe that the structure apparent in the data represents real structure. Any effect on the temperatures due to the higher altitudes would be common to each of these adjacent altitude segments and unlikely to introduce such variability. This altitude structure is probably similar to that reported in various ground-based lidar observations. This particular sequence ob- 


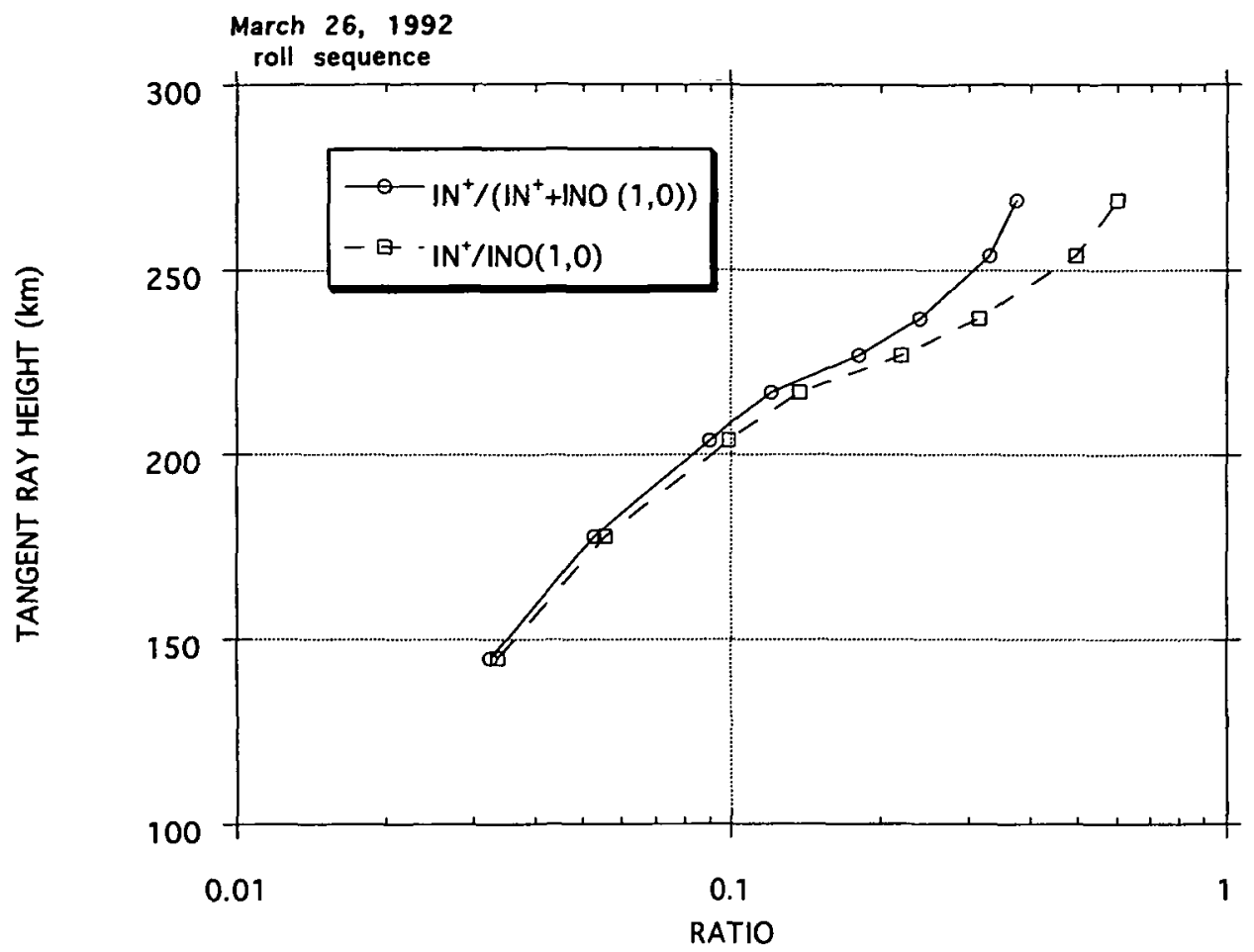

Figure 17. Percentage contribution to unresolved NO $\gamma(1,0)$ band and $\mathrm{N}^{+}\left({ }^{5} S\right)$ doublet of the $\mathrm{N}^{+}\left({ }^{5} S\right)$ doublet.

tained a number of such temperature images over a range of latitudes. (As the transitions ending in the $v^{\prime}=0$ level are self-absorbed at these altitudes, the populations are not correctly adjusted for these.)

The first spectral/spatial images of lower thermospheric NO was obtained with the ISO during the Spacelab 1 mission on December 7, 1983. As was done in the case of the ATLAS 1 sequence shown here, the field of view was directed at lower thermospheric altitudes, with the entrance slit perpendicular to the horizon, by controlling the orientation of the shuttle. This orientation was maintained while the shuttle covered a full orbit, during which time a series of six spectral scans were made with the instrument, covering a range of latitudes. The ground track for that set of observations is shown in Figure 20. An example of one of the Spacelab 1 spectral images is shown in Figure 21. These measurements were made with the tail of the orbiter pitched down toward the Earth so that the field of view was centered at approximately $104 \mathrm{~km}$. Relevant parameters for this data set are summarized in Table 6.

The temperature profile derived from the measurements is shown in Figure 22 compared with the effective temperature computed using MSIS neutral temperatures and modeled [NO] for the ATLAS 1 roll sequence shown for comparison. The Spacelab 1 data (again, fitting the $(1,1)$ band at these lower heights) show an effective temperature that is much hotter than can reasonably be expected from the model. The exospheric temperature at the time of the Spacelab 1 mission would have been closer to $1000 \mathrm{~K}$, lower than the $1200 \mathrm{~K}$ of the ATLAS 1 mission, so the modeled effective temperature for that case would be even lower than that shown for the ATLAS 1 case. The Spacelab 1 spectral data have shown repeated evidence for significant vehicle induced emissions. ATLAS 1 and the later missions appear to be relatively clean in terms of contamination. Major changes in the prelaunch processing of the vehicle and the payload have been introduced since 1983 . It is therefore possible that the hot temperatures indicated in Figure 22 are due to a significant vehicle induced population of hot NO, as NO is a likely major component of the induced environment.

We do not have accurate pointing information for the earlier Spacelab 1 data, and for that case the altitude uncertainties could be as large as $5 \mathrm{~km}$ or more at lower thermospheric altitudes. However, for the ATLAS 1 mission the pointing knowledge was greatly improved. The ISO tangent ray heights are computed from post mission orbiter position and attitude data. The dominant source of uncertainty is the determination of the instrument line of sight direction from the orbiter IMU (the primary vehicle star pointing system) attitude data. Pointing uncertainty for the ISO is believed to be less than $0.1^{\circ}(3$ sigma). The Pointing and Alignment Work Station (PAWS) investigation during ATLAS 1 determined a total pointing uncertainty of $0.2^{\circ}$ for pallet mounted instruments, including thermal drift $\left(0.08^{\circ}\right)$ and instrument alignment variations $\left(0.15^{\circ}\right)$. ISO observations were conducted from attitudes in which the payload bay would have been thermally stable compared to the solar pointing conditions under which the PAWS determination was made, so thermal drift should be negligible for the ISO during these observations. Furthermore, the alignment of ISO with the pallet as measured on the ground before and after the mission, varied by only $0.02^{\circ}$. Using post mission position data, the uncertainty in orbiter position is a negligible source of error in tangent ray heights. The tangent ray height calculations are done using a fully ellipsoidal Earth, and there are no approximations in the calculation other than assuming that there are no higher-order terms in the geoid. The maximum error from this source would be $100 \mathrm{~m}$. For the ISO the 

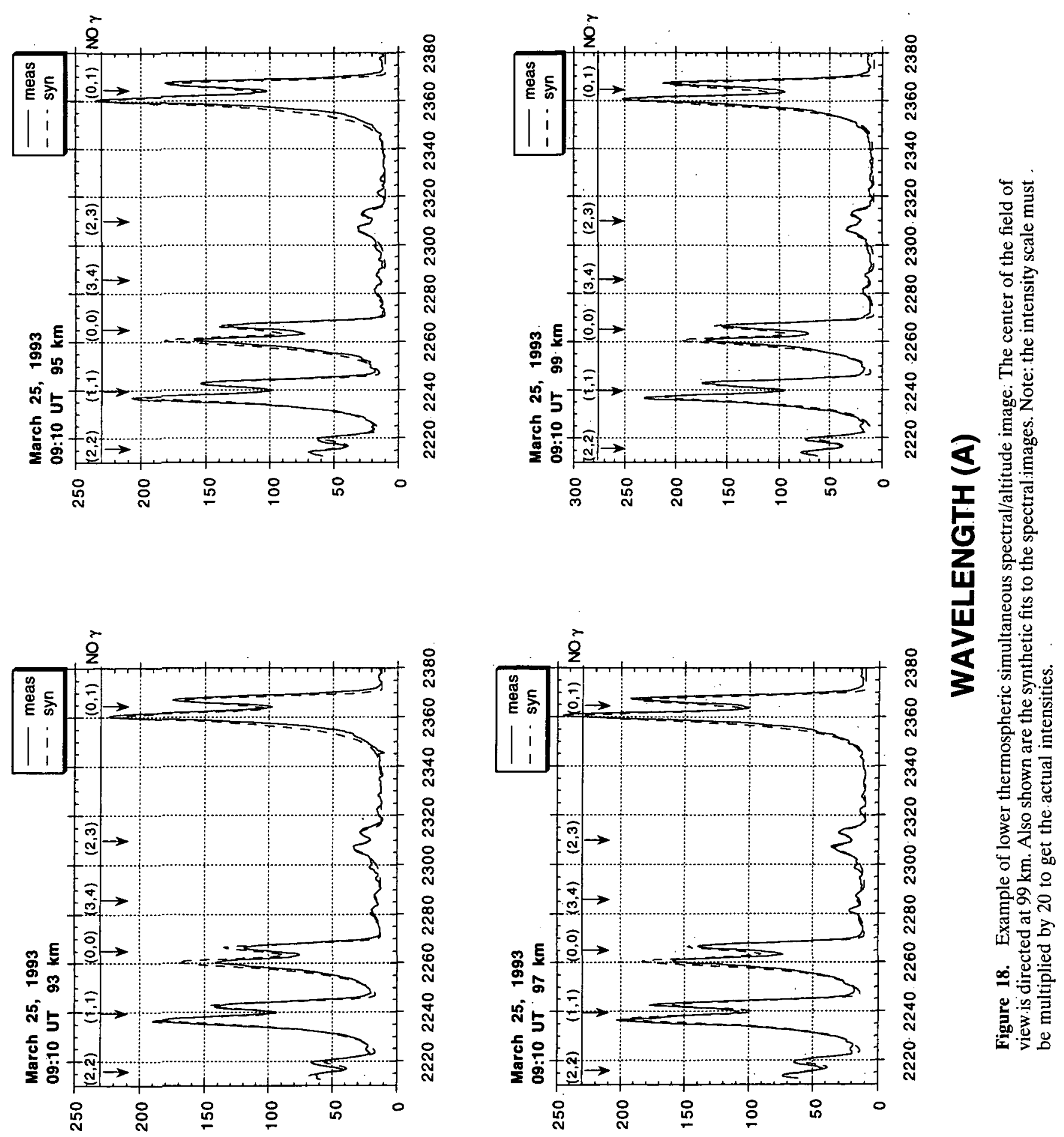

( $($ OZ/Y) ALISNGINI 

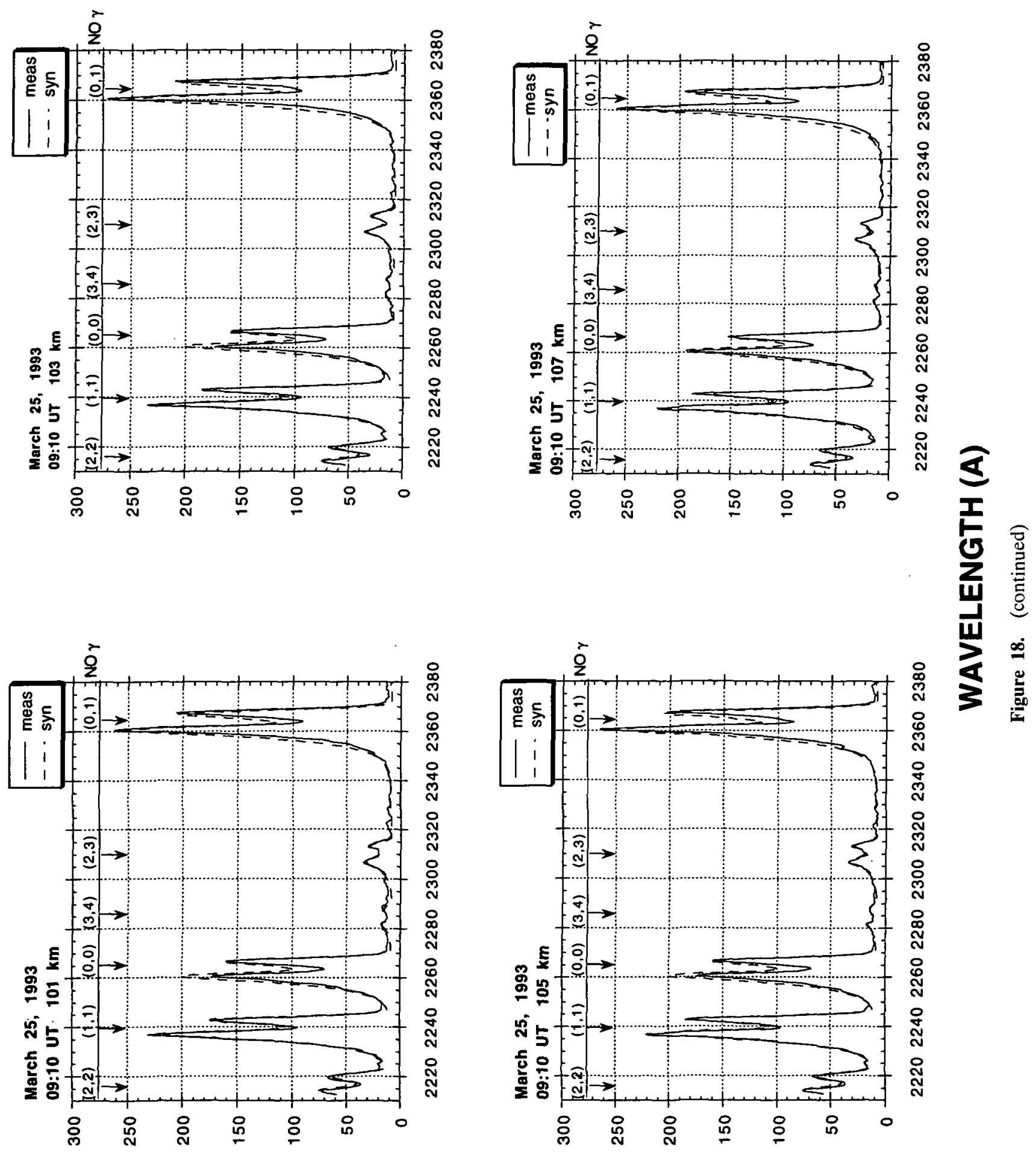


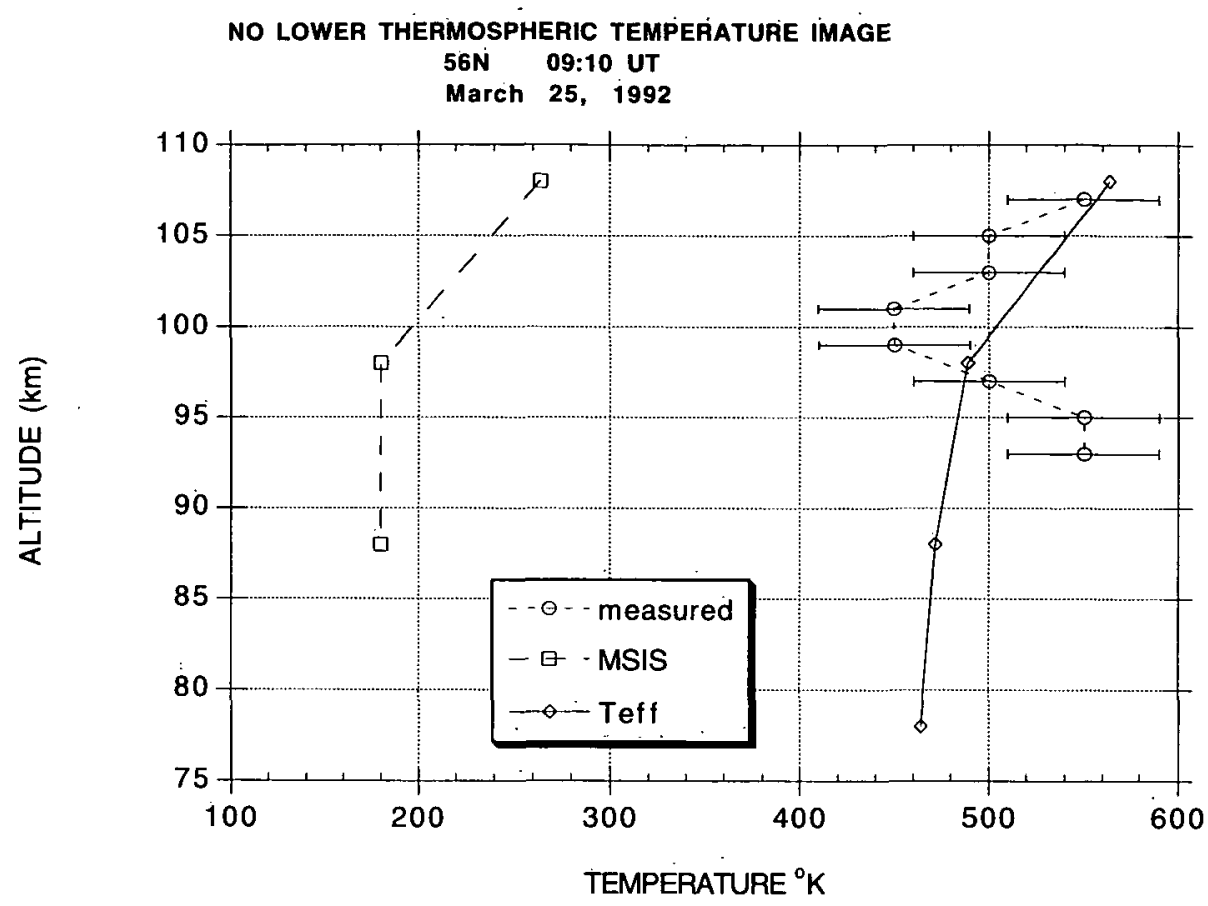

Figure 19. Temperature inferred from the NO $\gamma$ bands shown in Figures $1 \dot{8}$. Also shown is the computed effective temperature.

uncertainty in the tangent ray height for these sequences should be less than $3 \mathrm{~km}$ ( 3 sigma).

\section{NO $\varepsilon$ Bands}

As was shown in Figure 6, the $\mathrm{NO} \varepsilon$ bands are evident in the high latitude spectra, even above $140 \mathrm{~km}$. The $\mathrm{NO} \varepsilon$ bands are relatively weak but observable in the lower thermospheric data as can be seen from Figure 23 . Figure 23 shows the average of the nine lines that comprise the image of 93 to $107 \mathrm{~km}$. During the ATLAS 1 mission, spectral images near $100 \mathrm{~km}$ were not taken at a wavelength increment that includes the brighter $\varepsilon$ bands at shorter wavelengths, but these data were acquired on the earlier Spacelab 1 mission (Figure 21). Using the Spacelab 1 data, Bosserman [1989] was able to empirically infer the Frank-Condon factors. Since the emissions from the $(0,0)$; $(0,1),(0,2)$, and $(0,3)$ progression all have the same excitation mechanism, the relative intensities of these bands are determined by the Frank-Condon factors. Figure 24 shows Bosser-

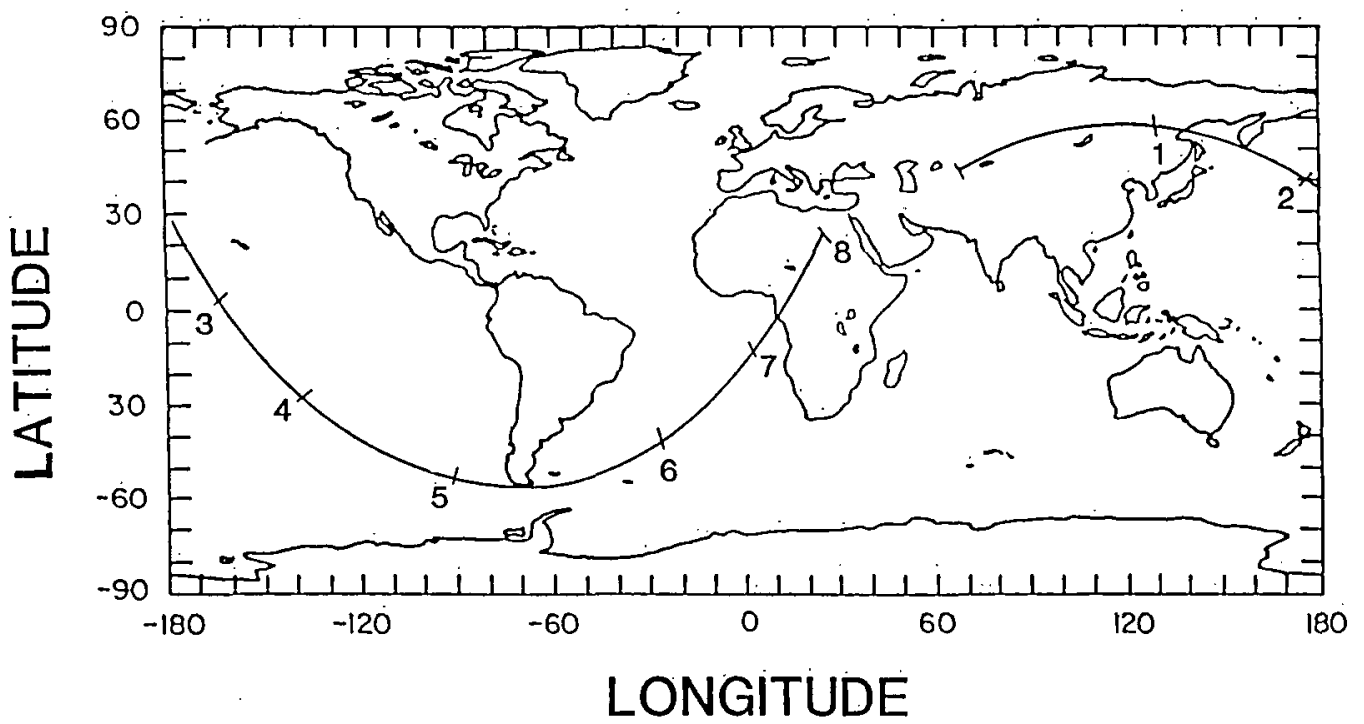

Figure 20. Ground track of shuttle during the sequence of lower thermospheric observations taken during the Spacelab 1 mission. A sequence of eight complete spectral scans was made and the numbers shown on the track indicate the location at which the NO gamma $(1,0)$ and neighboring bands were measured. The data shown in Figure 21 were taken from cycle 2, looking back along the track. 


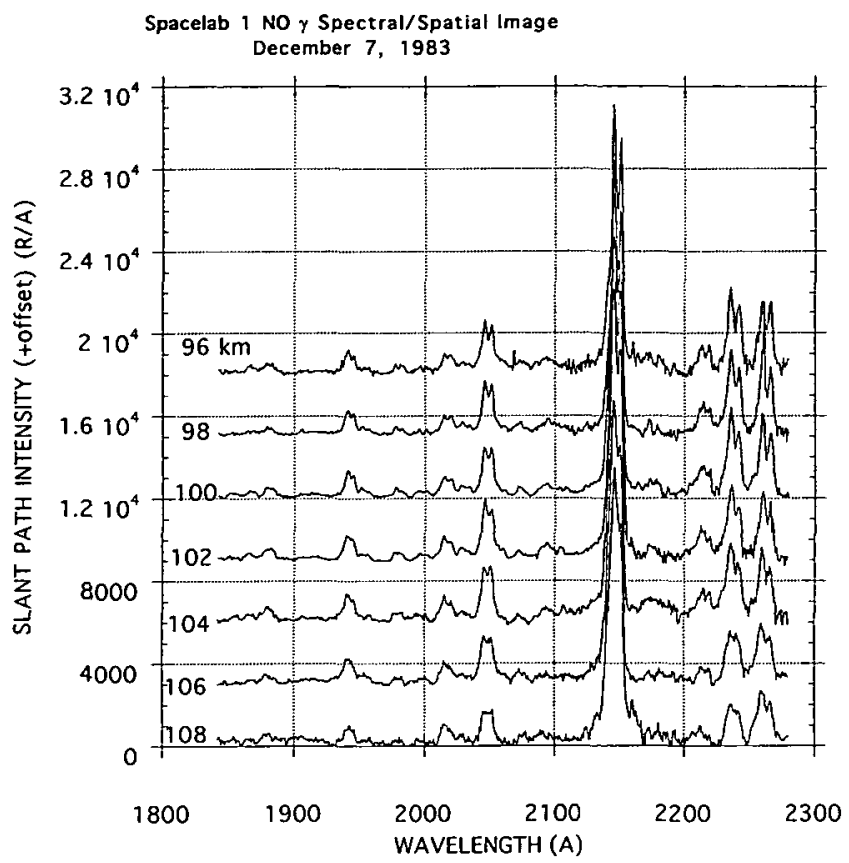

Figure 21. Spectral image measured during the Spacelab 1 mission on December 7, 1983. The data were obtained at a tangent ray height of $104 \mathrm{~km}$, at $37^{\circ} \mathrm{N}$ and $175^{\circ} \mathrm{E}$. The local time was 1007 and the solar zenith angle was $85^{\circ}$.

man's comparison of the Frank-Condon factors used in his synthetic spectral fit [Nicholls, 1964; Spindler et al., 1970] versus those determined from the data.

\section{NO $\delta$ Bands}

The $\delta$ bands have been reported in the twilight and nighttime emission spectrum [Cohen-Sabban and Vuillemin, 1973;

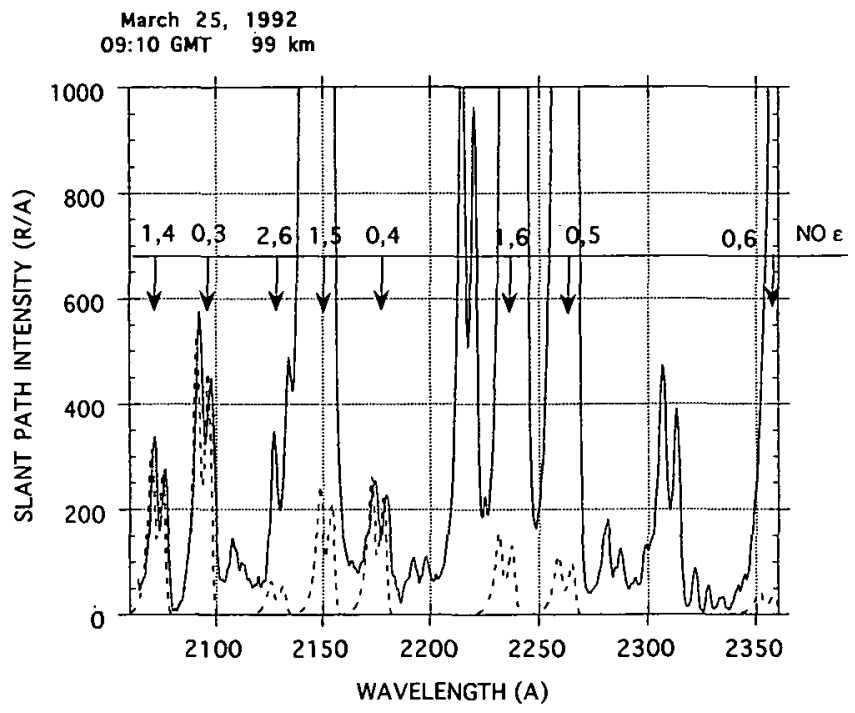

Figure 23. Example of spectral image shown in Figure 18, including the grating step to the short wavelength side. Several nonoverlapped $\varepsilon$ bands are evident, as well as weaker NO $\gamma$ bands.

Feldman and Takacs, 1974; Gerard, 1975]. Gerard [1975] reported a maximum total system intensity of $220 \mathrm{R}$, with a $(0,1)$ band intensity of $50 \mathrm{R}$. Feldman and Takacs [1974] reported a comparable $83 \mathrm{R}$ for the $(0,1)$ band. The source was believed to be preassociation of oxygen and nitrogen atoms above 140 $\mathrm{km}$ :

$$
\begin{aligned}
& \mathrm{N}\left({ }^{4} S\right)+\mathrm{O}\left({ }^{3} P\right) \rightarrow \mathrm{NO}\left(\mathrm{a}^{4} \Pi\right) \rightarrow \mathrm{NO}\left(\mathrm{C}^{2} \Pi, v^{\prime}=0\right) \\
& \rightarrow \mathrm{NO}\left(\mathrm{X}^{2} \Pi\right)+h \nu_{\delta}
\end{aligned}
$$

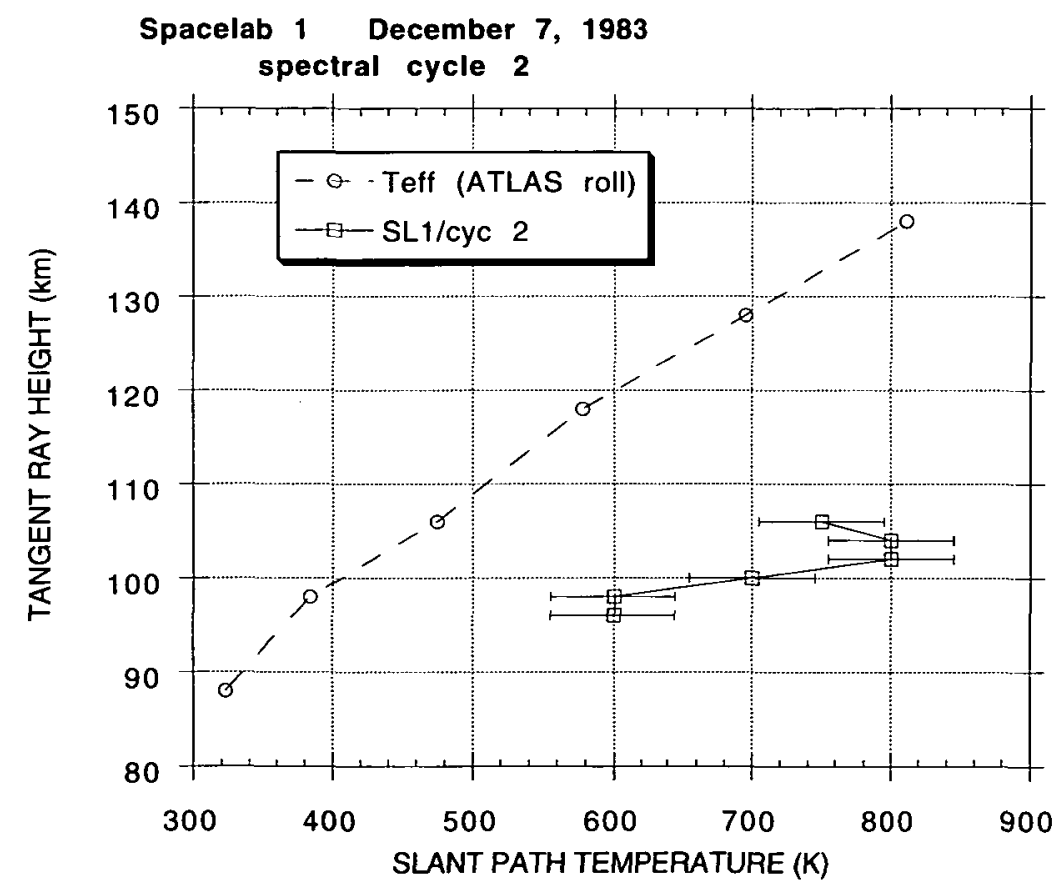

Figure 22. Temperature inferred from the NO $\gamma$ bands shown in Figures 21. Also shown is the computed effective temperature. 


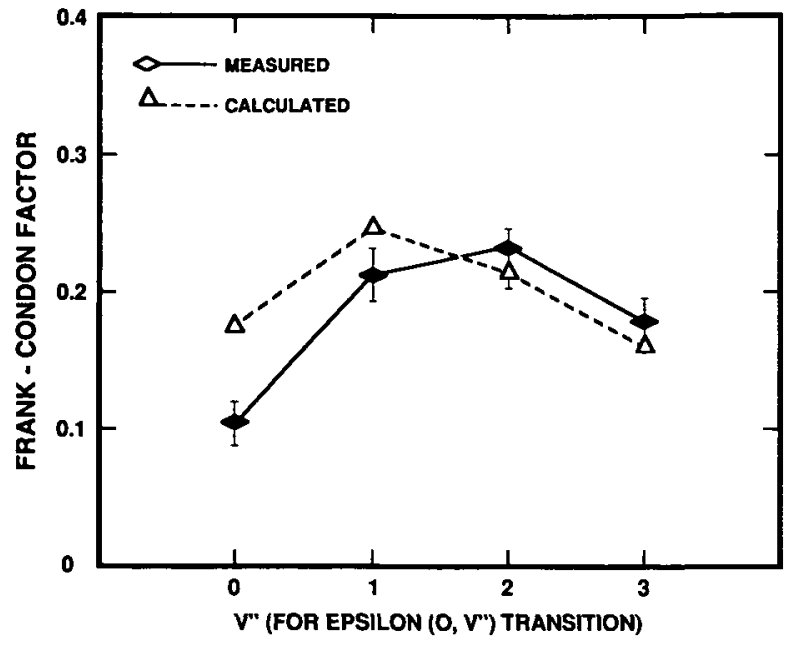

Figure 24. Theoretical versus empirically derived FrankCondon factors for the NO $\varepsilon$ bands [Bosserman, 1989] measured during the Spacelab 1 mission.
This source process is supported by the relative intensity of the $\gamma(1,0)$ and $\delta(0,0)$ bands in the Feldman and Takacs [1974] data, in which these two bands were found to be comparable in intensity. If the source were fluorescence, the $\gamma(1,0)$ band would be considerably brighter. The chemiluminescent $\delta$ bands are more easily seen at night because they are not swamped by the much brighter fluorescence bands of the $\gamma$ and $\varepsilon$ systems of NO.

Laboratory measurements by Callear and Pilling [1970a, b] were found to be consistent with a fluorescence efficiency of 0.03 , and it is this value that has been used in determining the branching for NO photodissociation products. Using this low value for the fluorescence efficiency, one would not expect to see the NO $\delta$ bands in the dayglow. However, McCoy [1983] and Cleary [1986] have reported the detection of the $\delta(1,0)$ band in daytime rocket experiments, and inferred the fluorescence efficiency to be much higher, 0.2 and 0.25 respectively. In fact, Cleary [1986] measured a column emission rate for the $\delta$ $(0,1)$ band at TRH of $100 \mathrm{~km}$ of $1-2 \mathrm{kR}$ and concluded that the

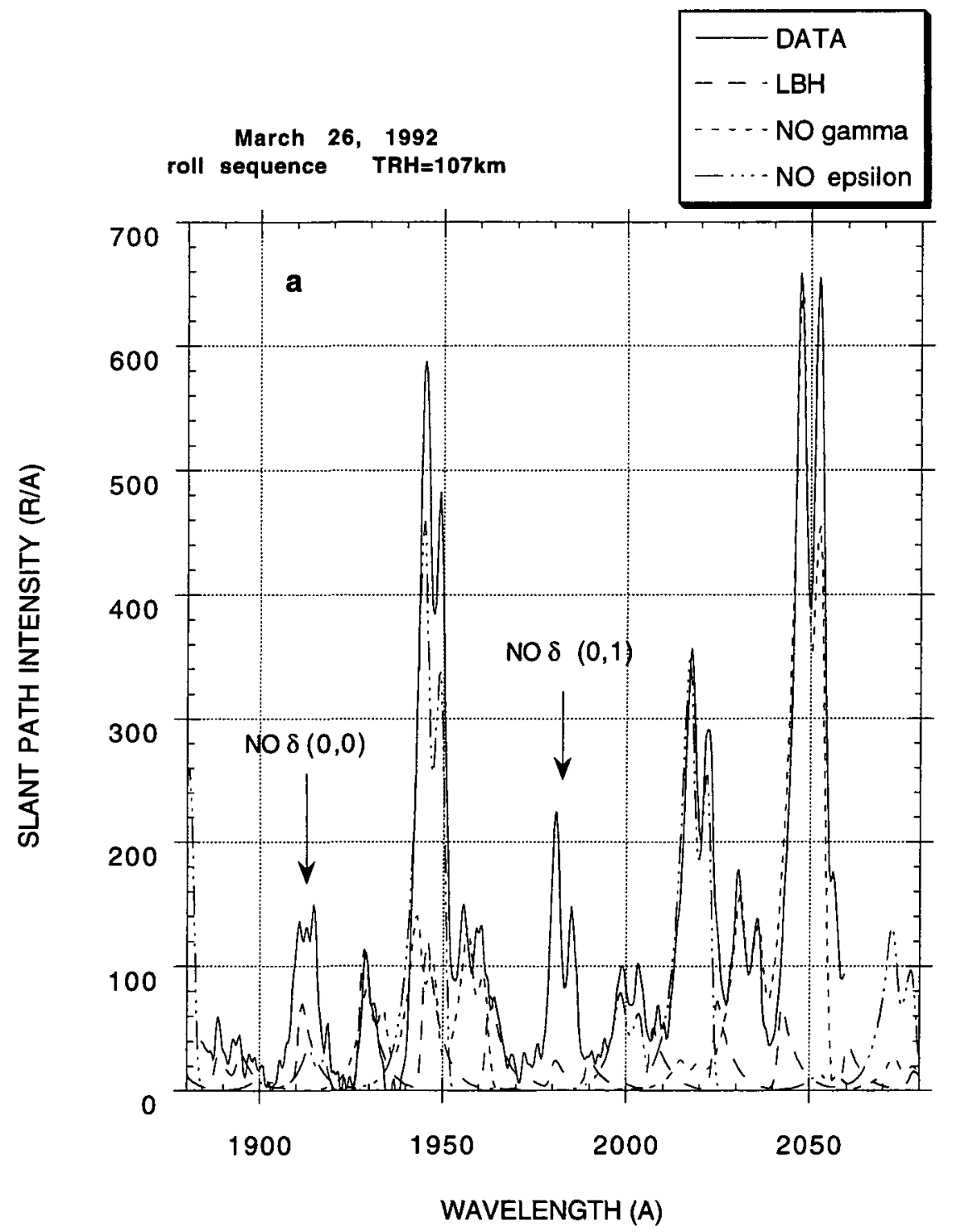

Figure 25. Portion of spectrum from ATLAS 1 roll sequence showing 2 TRHs: (a) $107 \mathrm{~km}$ and (b) $162 \mathrm{~km}$ : with NO $\gamma$ and $\varepsilon$ and $\mathrm{N}_{2} \mathrm{LBH}$ band synthetic fits. 


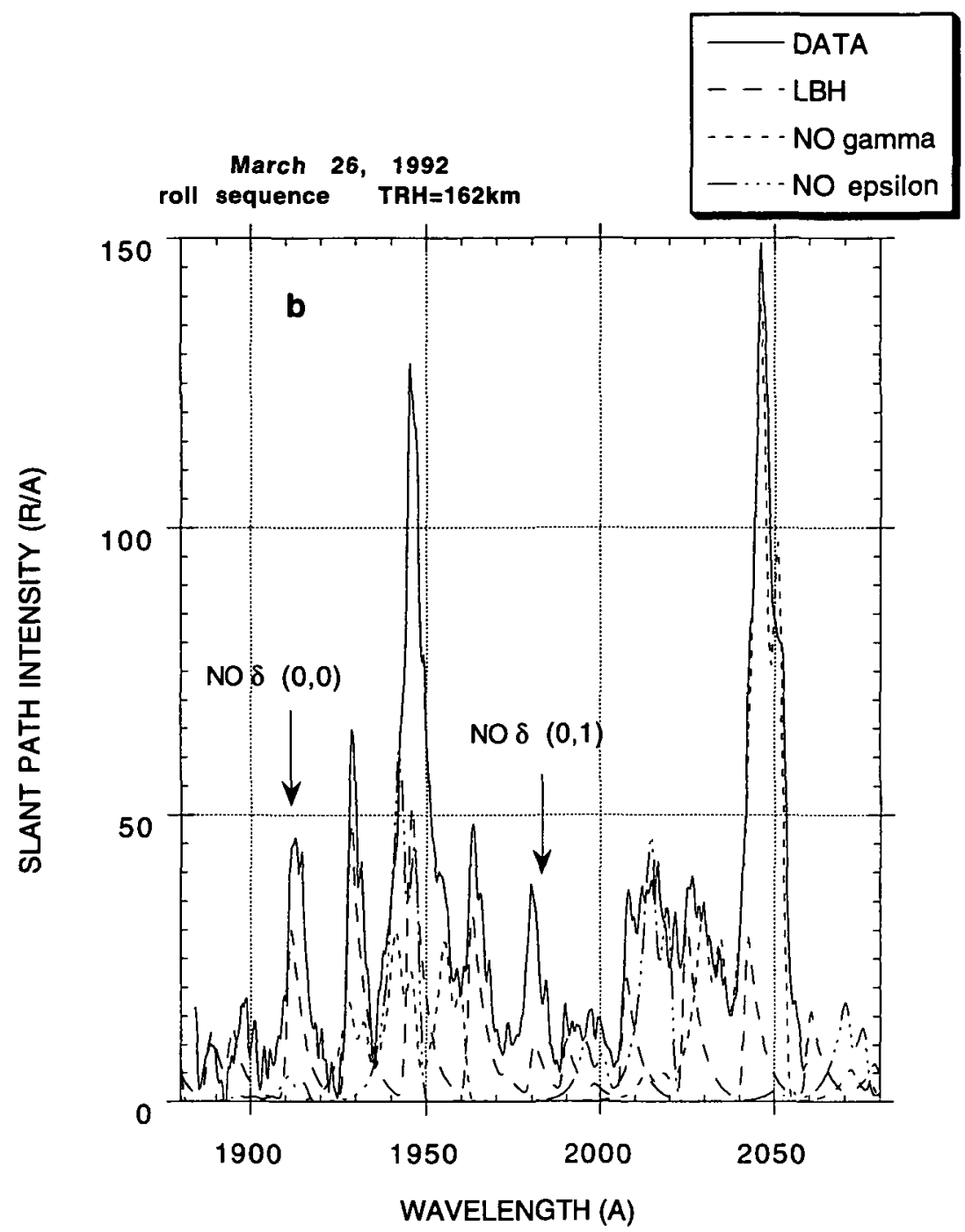

Figure 25. (continued)

fluorescence source of the $\delta$ bands is considerably stronger than the chemiluminescent source.

In an assessment of the Spacelab 1 ISO data shown in Figure 21, Bosserman [1989] inferred a fluorescence efficiency of 0.32 based on the intensity of the feature at $1984 \AA$ which he assumed to be the $\delta(0,1)$ band.

The ATLAS 1 data provide an opportunity to look for confirmation of the presence and relative intensity of $\delta$ bands. In laboratory measurements of the associative recombination process, only the $v^{\prime}=0$ level is populated [Groth et al., 1971], but if the results of Cleary [1986] are correct and fluorescence is the dominant daytime source of the $\delta$ bands, then bands from higher $v^{\prime}$ levels may also be present.

In the lower thermospheric imaging sequences made from the ATLAS 1 mission, in order to increase the temporal resolution, not all grating steps were used. As a result, we do not have data containing the $1984 \AA$ feature in this set. We do, however, have this portion of the spectrum in the roll maneuver sequence, and Figure 25a shows the lower-altitude ( $T R H=107 \mathrm{~km}$ ) image at this grating step. There is clearly a bright feature near $1984 \AA$. Figure 25 b shows a higher-altitude image (TRH $=162 \mathrm{~km}$ ) at this same grating step. Also shown in Figure 25a and 25b are the NO $\gamma$ and $\mathrm{N}_{2} \mathrm{LBH}$ synthetic spectral fits.

The slant path intensity of the $\delta(0,1)$ band is $\sim 1 \mathrm{kR}$ at a TRH of $107 \mathrm{~km}$. By $162 \mathrm{~km}$ (correcting for the underlying LBH $(6,13)$ band) it has dropped to $\sim 100 \mathrm{R}$. These results appear to support the conclusion of $M c$ Coy [1983] and Cleary [1986] that the fluorescence efficiency of the $\delta$ bands is considerably higher than that determined by Callear and Pilling [1970a, b].

\section{Conclusions}

In this paper we have analyzed FUV data over the wavelength range of approximately 1900 to $2400 \AA$ taken during the Spacelab 1 and ATLAS 1 shuttle missions with the Imaging Spectrometric Observatory. These data are used to derive altitude profiles of NO concentrations and temperature which are compared our global model and with other measurements. The NO concentrations during the ATLAS 1 mission lie to the high side of a sample of earlier measurements and are higher than predicted by our model. Because of its two-dimensional focal plane detectors, allowing imaging of wavelength and altitude, the flights of the instrument on the 1983 Spacelab 1 and 
1992 ATLAS 1 missions have provided the first simultaneously acquired altitude/spectral images of NO concentrations in the thermosphere. From the shape of the branches of the NO $\gamma$ bands, we have determined the neutral temperature. The results show that this is a viable technique for remote sensing of temperature down to the $80 \mathrm{~km}$ altitudes studied here, provided that data are also available on the NO at altitudes between the spacecraft and the tangent ray point, as the effect of the overlying NO is not insignificant for probing at these lower altitudes. The lower thermospheric temperature profile is quite structured in altitude. Temperature images obtained from the earlier Spacelab 1 mission indicate much higher than expected temperatures, probably due to a hot NO population in the induced environment of that mission.

The NO $\delta$ band intensities are consistent with other findings of a higher fluoresence efficiency than had been earlier determined from laboratory measurements.

The spectral resolution of the instrument is sufficient not only to separate the NO $\gamma(1,0)$ band and the $\mathrm{N}^{+}\left({ }^{5} S\right)$ doublet but also to resolve the two lines in the doublet. Below $200 \mathrm{~km}$, the $\mathrm{N}^{+}\left({ }^{5} S\right)$ feature contributes less than $10 \%$ to the unresolved combination of $\mathrm{N}^{+}\left({ }^{5} S\right)$ and NO $\gamma(1,0)$. The selfabsorption of the NO $\gamma(1,0)$ band is evident up to $150 \mathrm{~km}$ and appears to be present up to approximately $200 \mathrm{~km}$.

Acknowledgments. We thank the flight crew, C. Bolden, B. Duffy, D. Leestma, K. Sullivan, B. Lichtenberg, M. Foale, and D. Frimout for their invaluable assistance in performing the special maneuvers necessary to carry out this study, and the mission cadre of the ATLAS 1 mission, led by A. O'Neil and P. Nelson, for their support in making the observations possible. The synthetic spectral code used in this study was provided to us by J. Arnold and S. Langhoff of NASA Ames Research Center. Thanks go to D. Billups who worked on some of the early processing of the data used in this study. This work was supported by contract NAS8-37106 and NASA grant NAGW-3692 to the University of Alabama in Huntsville.

The Editor thanks S. C. Solomon for his assistance in evaluating this paper.

\section{References}

Abdou, W. A., D. G. Torr, P. G. Richards, M. R. Torr, and E. L. Breig, Results of a comprehensive study of the photochemistry of $\mathrm{N}_{2}^{+}$in the ionosphere, J. Geophys. Res., 89, 9060, 1984.

Abreu, V. J., J. H. Yee, S. C. Solomon, and A. Dalgarno, The quenching rate of $O\left({ }^{1} D\right)$ by $O\left({ }^{3} P\right)$, Planet. Space Sci., 11, 1143, 1986.

Adams, N. G., and D. Smith, Production distributions for some ionmolecule reactions, J. Phys. B, 9, 1439, 1976.

Albritton, D. L., Ion-neutral reaction-rate constants measured in flow reactors through 1977, Atomic Data Nucl. Data Tables, 22, 1, 1978.

Arnold, J. O., E. E. Whiting, and G. C. Lyle, Line by line calculation of spectra from diatomic molecules and atoms assuming a Voight line profile, J. Quant. Spectrosc. Radiative Transfer, 9, 775, 1969.

Banks, P. M., and G. Kockarts, Aeronomy, Part A, p. 225, Academic, San Diego, Calif., 1973.

Barth, C. A., Chemical Reaction in the Lower and Upper Atmosphere, p. 303, John Wiley, New York, 1961.

Barth, C. A., Rocket measurement of the nitric oxide dayglow, $J$. Geophys. Res., 69, 3301, 1964.

Barth, C. A., Ultraviolet spectroscopy of planets, report, Jet Propul. Lab., Pasadena, Calif., 1965.

Barth, C. A., The ultraviolet spectroscopy of planets, in The Middle Ultraviolet: Its Science and Technology, John Wiley, p. 177, New York, 1966.

Barth, C. A., and F. G. Eparvier, A method of measuring the temperature of the lower thermosphere, J. Geophys. Res., 98, 9437, 1993.

Barth, C. A., W. K. Tobiska, D. E. Siskind, and D. D. Cleary, Solarterrestrial coupling: Low-latitude thermospheric nitric oxide, Geophys. Res. Lett., 15, 92, 1988.
Bates, D. R., and E. C. Zipf, The $\mathrm{O}\left({ }^{1} S\right)$ quantum yield from $\mathrm{O}_{2}^{+}$ dissociation recombination, Planet. Space Sci., 28, 1081, 1981.

Becker, K. H., W. Groth, and D. Z. Kley, The rate constant for the aeronomic reaction $\mathrm{N}+\mathrm{O}_{2}$, Naturforsch., 24a, 1280, 1969.

Bosserman, J. L., Analysis of thermospheric dayglow spectra from the Spacelab 1 shuttle mission, M. S. thesis, Naval Postgraduate School, 1989.

Brook, E., M. F. A. Harrison, and A. C. H. Smith, Measurements of the electron impact ionization cross sections of $\mathrm{He}, \mathrm{C}, \mathrm{O}$ and $\mathrm{N}$ atoms, J. Phys. B, 11, 3115, 1978.

Callear, A. B., and M. J. Pilling, Fluorescence of nitric oxide, 6, Predissociation and cascade quenching in the $\mathrm{NO} \mathrm{D}^{2} \Sigma^{+}(v=0)$ and NO $C^{2} \Pi(v=0)$, and the oscillator strengths of the $\varepsilon(0,0)$ and $\delta$ $(0,0)$ bands, Trans. Faraday Soc., 66, 1886, 1970a.

Callear, A. B., and M. J. Pilling, Fluorescence of nitric oxide, 7, Quenching rates of $\mathrm{NO} \mathrm{C}^{2} \Pi(v=0)$, its rate of radiation to the NO $\mathrm{A}^{2} \Sigma^{\prime}$, energy transfer efficiencies, and mechanisms of predissociation, Trans. Faraday Soc., 66, 1618, 1970 b.

Callear, A. B., and W. M. Smith, Fluorescence of nitric oxide, Trans. Faraday Soc., 59, 1720, 1963.

Cartwright, D. C., Electron impact excitation of the electronic states of $\mathrm{N}_{2}$, II, Integral cross sections at incident energies from 10 to $50 \mathrm{ev}$, Phys. Rev. A, 16, 1041, 1977.

Chang, T., D. G. Torr, P. G. Richards, and S. C. Solomon, Re-evaluation of the $\mathrm{O}^{+}\left({ }^{2} \mathrm{P}\right)$ reaction rate coefficients derived from Atmosphere Explorer C observations, J. Geophys. Res., 98, 15,589, 1993.

Chen, A., R. Johnson, and M. A. Biondi, Measurements of the $\mathrm{O}^{+}+$ $\mathrm{N}_{2}$ and $\mathrm{O}^{-}+\mathrm{O}_{2}$ reaction rates from 300 to $900 \mathrm{~K}, J$. Chem. Phys., $69,2688,1978$.

Cleary, D. D., Daytime high-latitude rocket observations of the NO $\gamma$, $\delta$ and $\varepsilon$ bands, J. Geophys. Res., 91, 11,337, 1986.

Cohen-Sabbin, J., and A. Vuillemin, Ultraviolet nightglow spectrum from 1900 A to 3400 A, Astrophys. Space Sci., 24, 127, 1973.

Cravens, T. E., Nitric oxide gamma band emission rate factor, Planet. Space Sci., 25, 369, 1977.

Cravens, T. E., and A. I. Stewart, Global morphology of nitric oxide in the lower $E$ region, $J$. Geophys. Res., 83, 2446, 1978.

Cravens, T. E., J. Gerard, A. I. Stewart, and D. W. Rusch, The latitudinal gradient of nitric oxide in the thermosphere, J. Geophys. Res., 84, 2675-2680, 1979.

Dalgarno, A., Metastable species in the ionosphere, Ann Geophys., 26, 601, 1970.

Eparvier, F. G., and C. A. Barth, Self-absorption theory applied to rocket measurements of the nitric oxide $(1,0) \gamma$ band in the daytime thermosphere, J. Geophys. Res., 97, 13,723, 1992.

Erwin, E. H., A study of NO gamma bands in the mesosphere from Spacelab 1, M. S. thesis, Utah State Univ., Logan, 1985.

Fehsenfeld, F. C., The reaction of $\mathrm{O}_{2}^{+}$with atomic nitrogen and $\mathrm{NO}^{+}$ $\mathrm{H}_{2} \mathrm{O}$, and $\mathrm{NO}_{2}^{-}$with atomic oxygen, Planet. Space Sci., 25, 195, 1977.

Feldman, P. D., and Takacs, P. Z., Nitric oxide gamma and delta band emission at twilight, Geophys. Res. Lett., 1, 169, 1974.

Fennelly, J., and D. G. Torr, Photoionization and photoabsorption cross sections of $\mathrm{O}, \mathrm{N}_{2}, \mathrm{O}_{2}$ and $\mathrm{N}$ for aeronomic calculations, Atomic Data Nucl. Data Tables, 51, 321, 1992.

Fischer, C. F., and H. P. Saha, Multiconfiguration Hartree-Fock results with Briet-Pauli corrections for forbidden transitions in the $2 P^{4}$ configuration, Phys. Rev. A., 28, 3169, 1983.

Flesch, G. D., and C. Y. Ng, Absolute state-selected total cross sections for the $\mathrm{O}^{+}\left({ }^{2} D,{ }^{2} P\right)+\mathrm{N}_{2}$ reactions, J. Geophys. Res., 96, 21,407, 1991.

Frederick, J. E., and D. W. Rusch, On the chemistry of metastable atomic nitrogen in the $F$ region deduced from simultaneous satellite measurement of the $5200 \mathrm{~A}$ airglow and atmospheric composition, $J$. Geophys. Res., 82, 3509, 1977.

Gerard, J.-C., Satellite observations of the nitric oxide nightglow, Geophys. Res. Lett., 2, 179, 1975.

Gerard, J.-C., R. G. Roble, D. W. Rusch, and A. I. Stewart, The global distribution of thermospheric odd nitrogen for solstice conditions during solar cycle minimum, J. Geophys. Res., 89, 1725, 1984.

Gilmore, F. R., Potential energy curves for $\mathrm{N}_{2}, \mathrm{NO}, \mathrm{O}_{2}$, and corresponding ions, Memo. RM-4034-1-PR, p. 1, U.S. Airforce Project Rand, The Rand Corporation, Santa Monica, Calif., April 1986.

Groth, W., D. Kley, and U. Schurath, Rate constant for the infrared emission of the NO(C $\left.\mathrm{C}^{2} \Pi-\mathrm{A}^{2} \Sigma^{+}\right)$transition, J. Quant. Spect. Radiat. Trans., 11, 1475, 1971. 
Hedin, A. E., MSIS-86 thermospheric model, J. Geophys. Res., 92 $4649,1987$.

Henry, R. J. W., P. G. Burke, and A. L. Sinfailam, Scattering of electrons by C, N, O, N ${ }^{+}, \mathrm{O}^{+}$, and $\mathrm{O}^{++}$, Phys. Rev., 178, 218, 1969.

Huntress, W. T., and P. G. Anicich, On the reaction of $\mathrm{N}^{+}$ions with $\mathrm{O}_{2}$, Geophys. Res. Lett., 3, 317, 1976.

Johnsen, R., and M. A. Biondi, Laboratory measurements of the $\mathrm{O}^{+}\left({ }^{2} D\right)+\mathrm{N}_{2}$ and $\mathrm{O}^{+}\left({ }^{2} D\right)+\mathrm{O}_{2}$ reaction rate coefficients and their ionospheric implications, Geophys. Res. Lett., 7, 401, 1980.

Kernahan, J. H., and H. L. Pang, Experimental determination of absolute A coefficients for "forbidden" atomic oxygen lines, Can. J. Phys., 53, 455, 1975.

Kirby, K., E. R. Constantinides, S. Babeu, M. Oppenheimer, and G. A. Victor, Photoionization and photoabsorption cross-sections of thermospheric species; $\mathrm{He}, \mathrm{O}, \mathrm{N}_{2}$ and $\mathrm{O}_{2}$, At. Data Nucl. Data Tables, 23(1), 63, 1979.

Kley, D., G. M. Lawrence, and E. T. Stone, The yield of $\mathrm{N}\left({ }^{2} D\right)$ atoms in the dissociative recombination of $\mathrm{NO}^{+}, J$. Chem. Phys., 66, 4157 1977.

Kockarts, G., Nitric oxide cooling in the terrestrial thermosphere, Geophys. Res. Lett., 7, 137, 1980.

Langford, A. O., V. M. Bierbaum, and S. R. Leone, Auroral implications of recent measurement on $\mathrm{O}\left({ }^{1} S\right)$ and $\mathrm{O}\left({ }^{1} D\right)$ formation on the reaction of $\mathrm{N}^{+}$with $\mathrm{O}_{2}$, Planet. Space Sci., 33, 1225, 1985.

Lee, J. H., J. V. Michael, W. A. Payne, and L. J. Stief, Absolute rate of the reaction of $\mathrm{N}\left({ }^{4} S\right)$ with NO from $196-400 \mathrm{~K}$ with DF-RF and FP-RF techniques, J. Chemical Phys., 69, 3069, 1978.

Lin, C. L., and F. Kaufman, Reactions of metastable nitrogen atoms, J. Chem. Phys., 55, 3760, 1971.

Lindinger, W., F. C. Fehsenfeld, A. L. Schmeltekopf, and E. E. Ferguson, Temperature dependence of some ionospheric ion-neutra reactions from $300^{\circ}$ to $900^{\circ} \mathrm{K}, \mathrm{J}$. Geophys. Res., 79, 4753, 1974.

MacFarland, M., D. L. Albritton, F. C. Fehsenfeld, E. E. Ferguson, and A. L. Schmeltekopf, Energy dependence and branching ratio of the $\mathrm{N}_{2}^{+}+\mathrm{O}$ reaction, J. Geophys. Res., 79, 2925, 1974.

McCoy, R. P., Thermospheric odd nitrogen, 1, NO, N $\left({ }^{4} S\right), O\left({ }^{3} P\right)$ densities from rocket measurements of the NO $\delta$ and $\gamma$ bands and the $\mathrm{O}_{2}$ Herzberg I bands, J. Geophys. Res., 88, 3197, 1983.

McPeters, R. D., Climatology of nitric oxide in the upper stratosphere, mesosphere, and thermosphere: 1979 through 1986,J. Geophys. Res. 94, 3461, 1989.

Mehr, F. J., and M. A. Biondi, Electron temperature dependence of $\mathrm{O}_{2}^{-}$and $\mathrm{N}_{2}^{+}$ions with electrons, Phys. Rev., 181, 264, 1969.

Meier, R. R., Ultraviolet spectroscopy and remote sensing of the upper atmosphere, Space Sci. Rev., 58, 1, 1991.

Meira, L. G., Rocket measurements of upper atmospheric nitric oxide and their consequences to the lower ionosphere, J. Geophys. Res., 76, 202, 1971.

Nicholls, R. W., Frank-Condon factors to high vibrational quantum numbers IV: NO band systems, J. Res. Natl. Bur. Stand., 68A,(5), 1964.

Nicolet, M., Contribution a l'etude de la structure de l'ionosphere, Mem. Meteorol. Belg., 13, 83, 1945.

Nicolet, M., Ionospheric processes and nitric oxide, J. Geophys. Res., 70, 691, 1965a.

Nicolet, M., Nitrogen oxides in the chemosphere, J. Geophys. Res., 70 , $679,1965 b$

Nicolet, M., and S. Cieslik, The photodissociation of nitric oxide in the mesosphere and stratosphere, Planet. Space Sci., 28, 105, 1980.

Norton, R. B., and C. A. Barth, Theory of nitric oxide in the Earth's atmosphere, J. Geophys. Res., 75, 3903, 1970.

Piper, L. G., The reactions of $\left.\mathrm{N}^{2} P\right)$ with $\mathrm{O}_{2}$ and $\mathrm{O}, J$. Chem. Phys., 98, $8560,1993$.

Queffelec, J. L., B. R. Rowe, M. Morlais, J. C. Gomet, and F. Vallee, The dissociative recombination of $\mathrm{N}_{2}^{+}(v=0,1)$ as a source of metastable atoms in planetary atmospheres, Planet. Space Sci., 33, 263, 1985.

Richards, P. G., and D. G. Torr, An investigation of the consistency of the ionospheric measurements of the photoelectron flux and solar EUV flux, J. Geophys. Res., 89, 5625, 1984.

Richards, P. G., and D. G. Torr, Ratios of photoelectron to EUV ionization rates for aeronomic studies, J. Geophys. Res., 93, 4060, 1988.

Richards, P. G., and D. G. Torr, Auroral modeling of the $3371 \mathrm{~A}$ emission rate: Dependence on characteristic electron energy, J. Geophys. Res., 95, 10,337, 1990.
Richards, P. G., D. G. Torr, and M. R. Torr, Photodissociation of $\mathrm{N}_{2}$ : A significant source of thermospheric atomic nitrogen, J. Geophys. Res., 86, 1495, 1981.

Richards, P. G., M. R. Torr, and D. G. Torr, The seasonal effect of nitric oxide cooling on the thermospheric U. V. heat budget, Planet. Space Sci., 30, 515, 1982.

Richards, P. G., J. Fennelly, and D. G. Torr, EUVAC: Solar EUV flux model for aeronomic calculations, J. Geophys. Res., 99, 8981, 1994.

Rowe, B. R., D. W. Fahey, F. C. Fehsenfeld, and D. L. Albritton, Rate constants for the reactions of metastable $\mathrm{O}^{+}$ions with $\mathrm{N}_{2}$ and $\mathrm{O}_{2}$ at collision energies 0.04 to $0.2 \mathrm{eV}$ and the mobilities of these ions at 300 K, J. Chem Phys., 73, 194, 1980.

Rusch, D. W., Satellite ultraviolet measurements of nitric oxide fluorescence with a diffusive transport model, J. Geophys. Res., 78, 5676, 1973.

Rusch, D. W., J. C. Gerard, and W. E. Sharp, The reaction of $N\left({ }^{2} D\right)$ with $\mathrm{O}_{2}$ as a source of $\mathrm{O}\left({ }^{1} D\right)$ atoms in auroras, Geophys. Res. Lett., $5,1043,1978$.

Samson, J. A. R., and P. N. Pareek, Absolute photoionization cross sections of atomic oxygen, Phys. Rev. A, 31, 1470, 1985.

Seaton, M. J., and D. E. Osterbrock, Relative O II intensities in gaseous nebulae, Astrophys. J., 125, 66, 1957.

Siskind, D. E., C. A. Barth, and D. D. Cleary, The possible effect of solar soft X-rays on thermospheric nitric oxide, J. Geophys. Res., 95, 4311, 1990.

Slanger, T. G., and G. Black, Quenching of $\mathrm{O}\left({ }^{1} S\right)$ by $\mathrm{O}_{2}\left(a^{1} \Delta g\right)$, Geophys. Res. Lett., 8, 535, 1981.

Solomon, S., and R. R. Garcia, Transport of thermospheric NO to the upper stratosphere?, Planet. Space Sci., 32, 399, 1984.

Solomon, S., P. J. Crutzen, and R. G. Roble, Photochemical coupling between the thermosphere and the lower atmosphere, 1, Odd nitrogen from 50 to $120 \mathrm{~km}, J$. Geophys. Res., 87, 7206, 1982.

Spindler, R. J., L. Isaacson, and T. Wentink, Frank-Condon factors and R-centroids for the gamma system of NO, J. Quant. Spect. Radiat. Transfer, 10, 621, 1970.

Stewart, A. I., and T. E. Cravens, Diurnal and seasonal effects in $E$ region low-latitude nitric oxide, J. Geophys. Res., 83, 2453, 1978.

Streit, G. E., C. J. Howard, O. L. Schmeltekopf, J. A. Davidson, and H. I. Schiff, Temperature dependence of $O\left({ }^{1} D\right)$ rate constants for reactions with $\mathrm{O}_{2}, \mathrm{~N}_{2}, \mathrm{CO}_{2}, \mathrm{O}_{3}$, and $\mathrm{H}_{2} \mathrm{O}$, J. Chem. Phys., 65, 4761, 1976.

Strickland, D. J., and D. E. Anderson Jr, Radiation transport effects on the OI 1356 A limb intensity profile in the dayglow, J. Geophys. Res., $88,9260,1983$.

St. Maurice, J. P., and D. G. Torr, Nonthermal rate coefficients in the ionosphere: The reaction of $\mathrm{O}^{+}$with $\mathrm{N}_{2}, \mathrm{O}_{2}$, and $\mathrm{NO}, J$. Geophys. Res., 83, 969, 1978.

Thomas, R. J., A high-altitude rocket measurement of nitric oxide, $J$. Geophys. Res., 83, 513, 1978.

Torr, D. G., Refinement of aeronomically determined rate of coefficient for the reaction of $\mathrm{N}_{2}^{+}$with O, J. Geophys. Res., 84, 1939, 1979.

Torr, D. G., The photochemistry of the upper atmosphere, in The Photochemistry of Atmospheres, edited by J. S. Levine, p. 165, Academic, San Diego, Calif., 1985.

Torr, D. G., and M. R. Torr, Chemistry of the thermosphere and ionosphere, J. Atmos. Terr. Phys., 41, 797, 1979.

Torr, D. G., P. G. Richards, M. R. Torr, and V. J. Abreu, Further quantification of the sources and sinks of thermospheric $O\left({ }^{1} D\right)$ atoms, Planet. Space Sci., 29, 595, 1981.

Torr, D. G., M. R. Torr, and P. G. Richards, Thermospheric airglow emissions: A comparison of measurements from ATLAS-1 and theory, Geophys. Res. Lett., 20, 519, 1993.

Torr, M. R., The scientific objectives of the ATLAS-1 shuttle mission, Geophys. Res. Lett., 20, 487, 1993.

Torr, M. R., and D. G. Torr, The dissociative recombination of $\mathrm{O}_{2}^{+}$in the ionosphere, Planet. Space Sci., 29, 999, 1981.

Torr, M. R., and D. G. Torr, The NII 2143-A Dayglow from Spacelab 1, J. Geophys. Res., 90, 6679, 1985a.

Torr, M. R., and D. G. Torr, Ionization frequencies for solar cycle 21: Revised, J. Geophys. Res., 90, 6675, 1985b.

Torr, M. R., D. G. Torr, R. A. Ong, and H. E. Hinteregger, Ionization frequencies for major thermospheric constituents as a function of solar cycle 21, Geophys. Res. Lett., 6, 771, 1979.

Torr, M. R., D. G. Torr, and H. E. Hinteregger, Solar flux variability in the Schumann-Runge continuum as a function of solar cycle $21, J$. Geophys. Res., 85, 6063, 1980a. 
Torr, M. R., P. G. Richards, and D. G. Torr, A new determination of the ultraviolet heating efficiency of the thermosphere, J. Geophys, Res., 85, 6819, 1980b.

Torr, M. R., R. W. Basedow, and D. G. Torr, Imaging spectroscopy of the thermosphere from the Space Shuttle, Appl. Opt., 21, 4130, 1982.

Torr, M. R., R. W. Basedow, and J. Mount, An Imaging Spectrometric Observatory for Spacelab, Astrophys. Space Sci., 92, 237, 1983.

Torr, M. R., D. G. Torr, and R. R. Laher, The $\mathrm{O}_{2}$ atmospheric $0-0$ band and related emissions at night from Spacelab 1, J. Geophys. Res., 90, 8525, 1985.

Torr, M. R., D. G. Torr, P. G. Richards, and S. P. Yung, Mid- and low-latitude model of thermospheric emissions, $1, \mathrm{O}^{+}\left({ }^{2} P\right) 7320 \mathrm{~A}$ and $\mathrm{N}_{2}(2 P) 3371 \AA$, J. Geophys. Res., 95, 21,147, 1990.

Torr, M. R., et al., The first negative bands of $\mathbf{N}_{2}^{+}$in the dayglow from the ATLAS-1 shuttle mission, Geophys. Res. Lett., 20, 523, $1993 \mathrm{a}$.

Torr, M. R., D. G. Torr, and P. G. Richards, $\mathrm{N}\left({ }^{2} P\right)$ in the dayglow: Measurement and theory, Geophys. Res. Lett., 20, 531, 1993b.

Torr, M. R., D. G. Torr, T. Chang, P. Richards, and G. Germany, $\mathrm{N}_{2}$ Lyman-Birge-Hopfield dayglow from ATLAS 1, J. Geophys. Res., 99, 21,397, 1994.
Vaughan, S. O., and J. P. Doering, Absolute experimental differential and integral electron excitation cross sections for atomic oxygen, 2 , The $\left({ }^{3} P \rightarrow{ }^{3} S^{\circ}\right)$ transition $(1304 \AA)$ from $16.5 \mathrm{eV}$ to $200 \mathrm{eV}$ with comparison to atomic hydrogen, J. Geophys. Res., 91, 13,755, 1986. Victor, G. A., and A. Dalgarno, The $2145 \AA$ dayglow and the high altitude nitric oxide density, Geophys. Res. Lett., 9, 866, 1982.

Zipf, E. C., and P. W. Erdman, Electron impact excitation of atomic oxygen: Revised cross sections, J. Geophys. Res., 90, 11,087, 1985.

T. Chang, N. Li, P. Richards, W. Swift, and D. G. Torr, Optical Aeronomy Laboratory, University of Alabama in Huntsville, AL 35899.

M. R. Torr, Payload Projects Office, Marshall Space Flight Center, Huntsville, AL 35812.

(Received October 11, 1994; revised February 9, 1995; accepted March 28, 1995.) 